\title{
ATP/P2X7 axis modulates myeloid-derived suppressor cell functions in neuroblastoma microenvironment
}

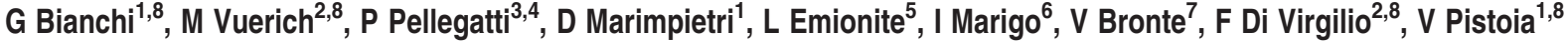 \\ and L Raffaghello*,1,8
}

Tumor microenvironment of solid tumors is characterized by a strikingly high concentration of adenosine and ATP. Physiological significance of this biochemical feature is unknown, but it has been suggested that it may affect infiltrating immune cell responses and tumor progression. There is increasing awareness that many of the effects of extracellular ATP on tumor and inflammatory cells are mediated by the P2X7 receptor (P2X7R). Aim of this study was to investigate whether: (i) extracellular ATP is a component of neuroblastoma (NB) microenvironment, (ii) myeloid-derived suppressor cells (MDSCs) express functional P2X7R and (iii) the ATP/P2X7R axis modulates MDSC functions. Our results show that extracellular ATP was detected in NB microenvironment in amounts that increased in parallel with tumor progression. The percentage of $\mathrm{CD}_{11 \mathrm{~b}}{ }^{+} / \mathrm{Gr}-1^{+}$cells was higher in NB-bearing mice compared with healthy animals. Within the CD11b/Gr-1 ${ }^{+}$population, monocytic MDSCs (M-MDSCs) produced higher levels of reactive oxygen species (ROS), arginase-1 (ARG-1), transforming growth factor- $\beta 1$ (TGF- $\beta 1$ ) and stimulated more potently in vivo tumor growth, as compared with granulocytic MDSCs (G-MDSCs). P2X7R of M-MDSCs was localized at the plasma membrane, coupled to increased functionality, upregulation of ARG-1, TGF- $\beta 1$ and ROS. Quite surprisingly, the P2X7R in primary MDSCs as well as in the MSC-1 and MSC-2 lines was uncoupled from cytotoxicity. This study describes a novel scenario in which MDSC immunosuppressive functions are modulated by the ATP-enriched tumor microenvironment.

Cell Death and Disease (2014) 5, e1135; doi:10.1038/cddis.2014.109; published online 20 March 2014

Subject Category: Immunity

The cellular composition of established tumors is heterogeneous as it includes malignant cells and non-transformed cellular elements such as stromal cells, microvessel lining endothelial cells and inflammatory cells. ${ }^{1-3}$ Among cells of innate immunity myeloid-derived suppressor cells (MDSCs), immature cells of myeloid origin, expand and are activated in response to growth factors released by tumors. ${ }^{4}$ As observed in cancer patients and experimental tumor models, MDSCs accumulate in blood, secondary lymphoid organs, bone marrow (BM) and at tumor sites where are responsible for tumor-associated immunosuppression. ${ }^{4}$

Tumor microenvironment is a complex milieu enriched with molecules released by malignant and inflammatory cells, including cytokines, chemokines, growth factors and purines. ${ }^{5}$ Among purines, extracellular ATP and adenosine (Ado) are potent modulators of immune cell responses and cytokine release and support cancer cell growth. ${ }^{6-8}$

ATP, a well-known danger signal molecule with proinflammatory properties, is released by virtually all cell types. ${ }^{5}$ Once accumulated in the tumor microenvironment, ATP exerts effects that are either beneficial or detrimental to the host depending on: (i) its concentration, (ii) the P2 receptor (P2R) subtypes and (iii) the expression levels of nucleotidedegrading enzymes, such as CD39 and CD73, in immune, tumor and stromal cells. ${ }^{5}$ CD39 and CD73 convert ATP into Ado, that in turn causes immunosuppression and may promote cancer cell growth. ${ }^{9-11}$ By directly interacting with P2Rs expressed by tumor cells, ATP may cause cell proliferation or cell death. Likewise, ATP may have an immunostimulatory or inhibitory effect on immune cells. ${ }^{5,12}$

\footnotetext{
${ }^{1}$ Laboratory of Oncology, Istituto Giannina Gaslini, Genoa, Italy; ${ }^{2}$ Department of Morphology, Surgery and Experimental Medicine, Section of General Pathology, Interdisciplinary Center for the Study of Inflammation, University of Ferrara, Ferrara, Italy; ${ }^{3}$ Department of Life Sciences and Biotechnology, Biochemistry and Molecular Biology Section, University of Ferrara, Ferrara, Italy; ${ }^{4}$ Laboratory of Clinical Chemistry and Microbiology, Azienda Ospedaliero-Universitaria, Sant'Anna Hospital, Ferrara, Italy; ${ }^{5}$ Animal Facility, IRCCS Azienda Ospedaliera Universitaria San Martino-IST Istituto Nazionale per la Ricerca sul Cancro, Genoa, Italy; ${ }^{6}$ Istituto Oncologico Veneto, IRCCS, Padova, Italy and ${ }^{7}$ Department of Pathology and Diagnostic, Immunology Section, Verona University Hospital, Verona, Italy *Corresponding author: L Raffaghello, Laboratory of Oncology, Istituto Giannina Gaslini, Via G. Gaslini 5, Genoa 16147, Italy. Tel: + 390105636342 ; Fax: + 39010 3779820; E-mail: lizziaraffaghello@ospedale-gaslini.ge.it

${ }^{8}$ These authors equally contributed to this work.

Keywords: ATP; myeloid-derived suppressor cells; neuroblastoma; purinergic receptors; P2X7 receptor

Abbreviations: P2X7R, P2X7 receptor; MDSCs, myeloid-derived suppressor cells; M-MDSCs, monocytic MDSCs; G-MDSCs, granulocytic MDSCs; Ado, adenosine; P2R, P2 receptor; DCs, dendritic cells; NB, neuroblastoma; pmeLUC, plasma membrane luciferase; BLI, bioluminescence imaging; BM, bone marrow; PB, peripheral blood; TF, tumor-free; ARG-1, arginase-1; ROS, reactive oxygen species; TGF- $\beta 1$, transforming growth factor- $\beta 1$; G, granulocytic; M, monocytic; BzATP, benzoyl-ATP; OATP, oxidized ATP; EtBr, ethidium bromide; LPS, lipopolysaccharides; LDH, lactate dehydrogenase; STAT, Signal Transducer and Activator of Transcription; NO, nitric oxide; FBS, fetal bovine serum; DCFDA, dichlorodihydrofluorescein diacetate; GAPDH, glyceraldehyde 3-phosphate dehydrogenase; Bisoxonol, bis[11,3-diethylthiobarbiturate trimethineoxonal]
}

Received 11.12.13; revised 10.2.14; accepted 19.2.14; Edited by A Verkhratsky 
The P2R family is comprised of the P2YR and P2XR subfamilies. P2YR are seven-membrane-spanning, G-protein-coupled receptors, whereas $\mathrm{P} 2 \mathrm{X}$ are cation selective ion channels. Among P2XR, particular attention has been focused on P2X7R, an ion channel characterized by two distinct permeability states coupled to opposite cellular responses, that is, either cell proliferation or cytotoxicity. ${ }^{13-18}$ In addition, a role for P2X7R in immune cell recruitment and activation, and immune cell-mediated cancer cell death has been demonstrated. ${ }^{19,20}$ Specifically, P2X7R expressed by dendritic cells (DCs) triggers IL- $1 \beta$ release and consequent stimulation of $\mathrm{CD}^{+}{ }_{-}$and $\mathrm{CD}^{+}{ }^{+}$-mediated anti-tumor responses. ${ }^{21}$

Neuroblastoma (NB), a malignant neoplasia originating from the sympathetic nervous system, is the second most common solid tumor in children. About $50 \%$ of NB patients present with metastatic disease at diagnosis, and only onethird of them survives at 5 years despite surgery, radiotherapy and aggressive chemotherapy followed by autologous hematopoietic rescue. ${ }^{22}$

Recently, MDSCs have been identified for the first time in both NB tumor-bearing mice and NB patients. ${ }^{23}$ However, factors responsible for the modulation of immune responses of MDSC activity and functions released from NB tumorbearing hosts are incompletely known.

Aim of this study was the investigation of P2X7R expression and function in MDSC subsets isolated from a syngeneic model of NB-bearing mouse.

Our results demonstrate that $\mathrm{P} 2 \mathrm{X} 7 \mathrm{R}$ expression and function are different in either granulocytic or monocytic MDSCs (G- or M-MDSCs), thus allowing a divergent modulation of the two different MDSC subsets by extracellular ATP. This is of particular relevance as we found that high levels of extracellular ATP are specifically detected in the NB tumor microenvironment and that they increase in parallel with tumor progression. This study describes a novel function of P2X7R and highlights the crucial role of the ATP/P2X7R axis in dictating the immunosuppressive properties of the tumor microenvironment.

\section{Results}

ATP detection in NB tumor microenvironment. In order to detect extracellular ATP in NB microenvironment, the murine NB NXS2 cell line was stably transfected with the plasma membrane luciferase (pmeLUC) probe (pmeLUCNXS2), and intravenously injected into immunocompetent syngeneic $\mathrm{A} / \mathrm{J}$ mice. Bioluminescence imaging (BLI) analysis of mice disclosed a diffuse luminescence in the peritoneal cavity, associated with specific light-emitting spots in the kidneys, adrenal gland and ovaries, that is, at sites of tumor metastasis (Figure 1a). BLI was carried out for up to 26 days after tumor cell inoculum, showing an increased emission intensity as tumor progressed. Direct BLI of the excised masses, consistently showed that light-emitting foci coincided with tumor masses (Figure 1b). These results indicate that extracellular ATP was specifically detected within tumor masses in NB-bearing mice in amounts that increased in parallel with tumor progression.

Identification and functional characterization of G- and M-MDSC subsets from NB-bearing mice. In order to identify and characterize MDSC subsets in the NB-bearing mice, single-cell suspensions obtained from spleen, BM and peripheral blood (PB) of tumor-free (TF) and NB-bearing
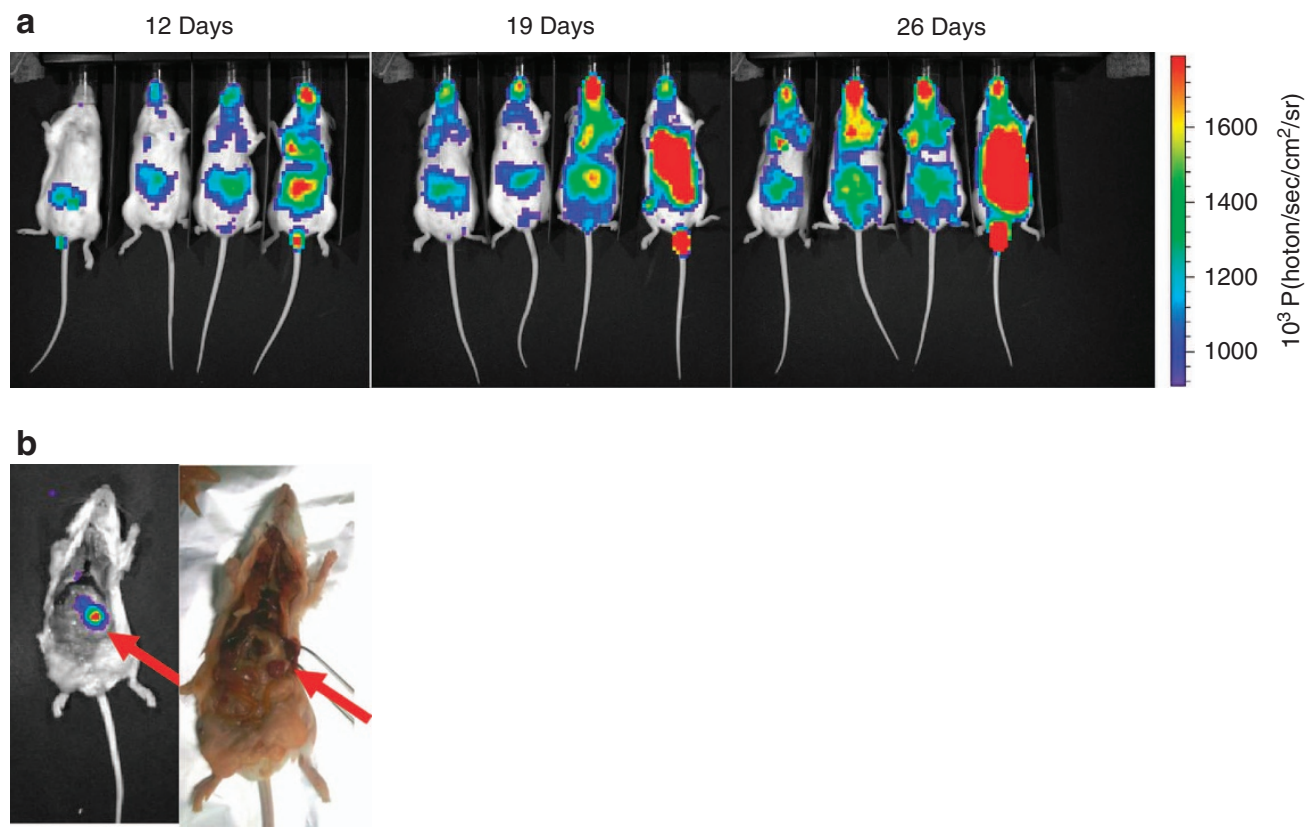

Figure 1 ATP detection in NB tumor microenvironment by pmeLUC probe. Immunocompetent A/J mice $(n=4)$ were i.v. injected with pmeLUC-NXS2 cells $\left(2 \times 10^{5}\right.$ cells/ mouse). Panel a shows the animals imaged by bioluminescence 12,19 and 26 days after tumor cell inoculum. Panel b shows a representative animal subjected to postmortem macroscopic analysis. A light-emitting metastasis localized in the abdominal cavity is indicated by red arrow. This is a representative experiment out of three performed 
mice were evaluated by flow cytometry. We found that the percentage of CD11b ${ }^{+} / \mathrm{Gr}-1^{+}$cells in the spleen (Figures $2 a$ and b) and in the PB (Figures $2 \mathrm{c}$ and d), but not in the BM (Figures $2 e$ and $f$ ) of NB tumor-bearing mice was significantly higher compared with TF mice.

On the basis of the differential expression of Ly-6G and Ly-6C markers, ${ }^{24}$ we investigated the presence of G- and M-MDSCs from NB-bearing mice. The amount of G-MDSCs and M-MDSCs isolated from NB mice by immunomagnetic sorting was significantly higher compared with that isolated from TF mice (Figure $2 \mathrm{~g}$ ).

TF and NB G-MDSCs and M-MDSCs subsets were then tested for arginase-1 (ARG-1) expression, and reactive oxygen species (ROS) and transforming growth factor- $\beta 1$ (TGF- $\beta 1$ ) secretion. Figures $3 a$ and $b$ show that NB M-MDSCs expressed significantly higher levels of ARG-1 in comparison with TF M-MDSCs. In contrast, no ARG-1 expression was detected in TF and NB G-MDSCs (Figure $3 b$ ). Figure $3 c$ shows that NB M-MDSCs and NB G-MDSCs had an enhanced ability to release ROS compared with TF MDSCs. Furthermore, NB M-MDSCs produced a strikingly higher amount of ROS compared with NB G-MDSCs. As shown in Figure $3 d$ in both NB and TF animal models, M-MDSCs secreted significantly higher amounts of TGF- $\beta 1$ in comparison with G-MDSCs.

We also tested whether NB M-MDSCs and NB G-MDSCs promoted in vivo tumor progression. Figure $3 e$ shows that the size of tumors generated by co-inoculation of NB NXS2-LUC cells and NB M-MDSCs were significantly higher compared with that of control tumors (only NB cells) and tumors developed by co-injection of NB cells and NB G-MDSCs.

Secretion of different cytokines and chemokines was assessed in the supernatants of NB M-MDSCs and G-MDSCs. TF and NB MDSCs show similar production of cytochine/chemokines levels, with the exception of $\mathrm{IL}-1 \beta$, CCL11 and CCL2 (Table 1). IL-1 $\beta$ was found increased in both NB MDSC subtypes, but to a higher extent in M-MDSCs compared with G-MDSCs. On the contrary, CCL11 and CCL2 were slightly downregulated in NB MDSCs versus TF MDSCs.

Taken together, these results show that M-MDSCs are the main MDSC source of key immunosuppressive factors such as ARG-1, ROS and TGF- $\beta 1$. a

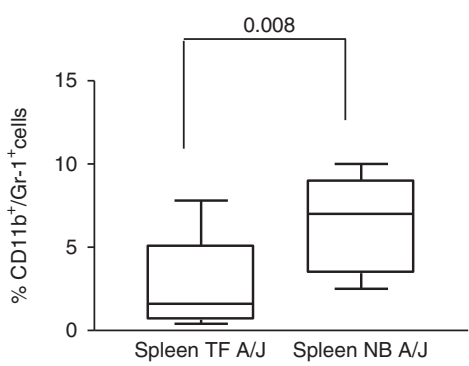

C

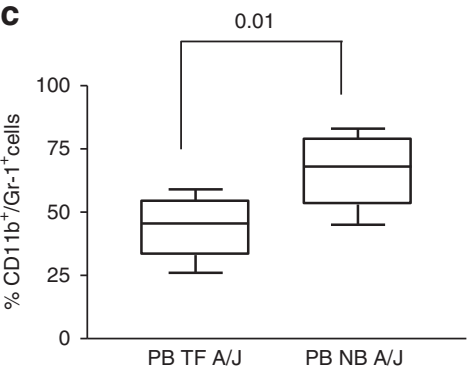

e

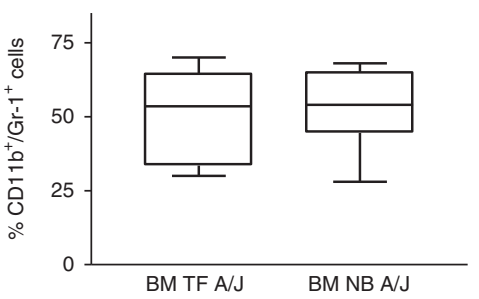

b
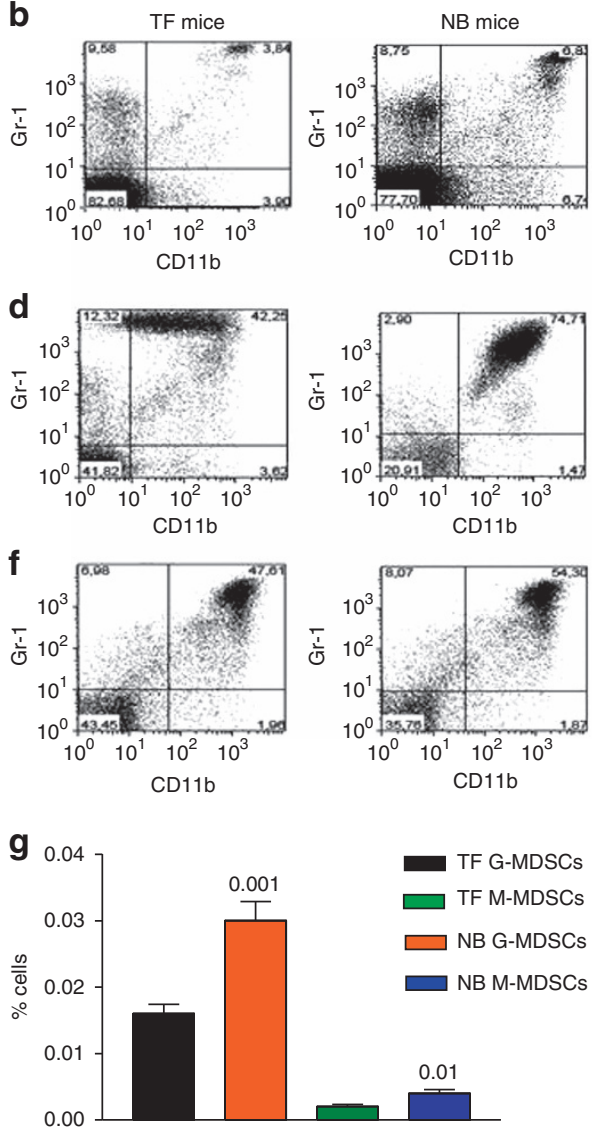

Figure 2 Accumulation of MDSCs in NB tumor-bearing mice. Single-cell suspension isolated from spleen, PB and BM of TF and NB tumor-bearing (NB) mice (mice/group $n=15)$ were stained with CD11b and anti-Gr-1 antibodies and subjected to flow cytometry analysis. Panels $\mathbf{a}, \mathbf{c}$ and $\mathbf{e}$ show the percentage of $\mathrm{CD} 11 \mathrm{~b}^{+} / \mathrm{Gr}-1^{+}$cells in spleen, PB and BM from TF and NB mice. $P$ values were calculated using unpaired $t$-test with Welch's correction. Panels $\mathbf{b}, \mathbf{d}, \mathbf{f}$ show a representative example of flow cytometry analysis of $\mathrm{CD} 11 \mathrm{~b}^{+} / \mathrm{Gr}-1^{+}$cells in spleen, PB and BM from TF and NB mice. Panel $\mathbf{g}$ shows the percentage of G-MDSCs and M-MDSCs subsets isolated from the spleen of TF and NB tumor-bearing (NB) mice using the Murine Myeloid Derived Suppressor Cells Isolation Kit. Data are expressed as mean value of the percentages of M-MDSC and G-MDSC cells \pm S.D. $P$-value was calculated using unpaired $t$-test with Welch's correction in NB-bearing mice 
a

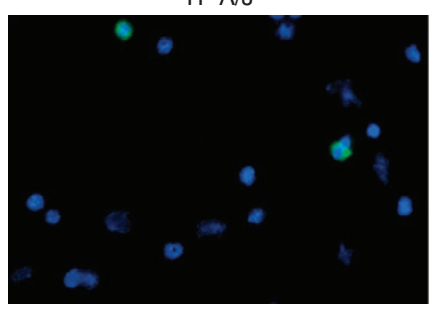

ARG-1 expression

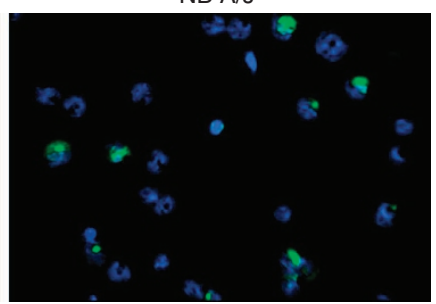

ARG-1 expression

C

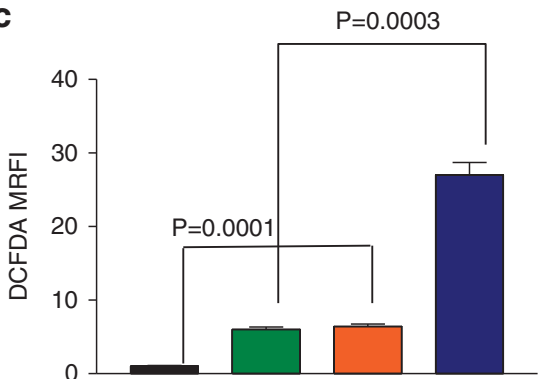

d

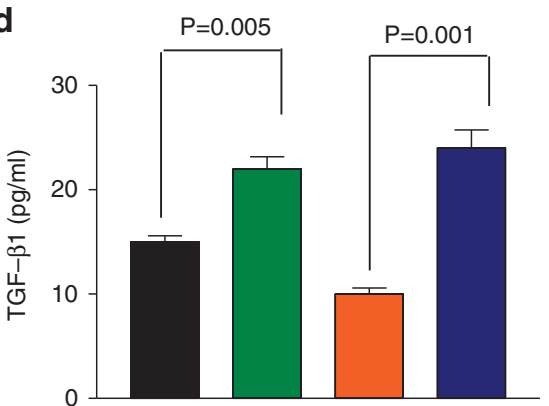

b

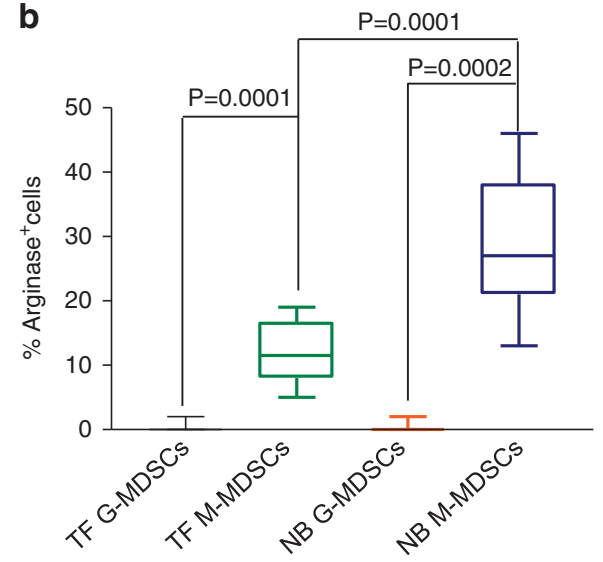

e
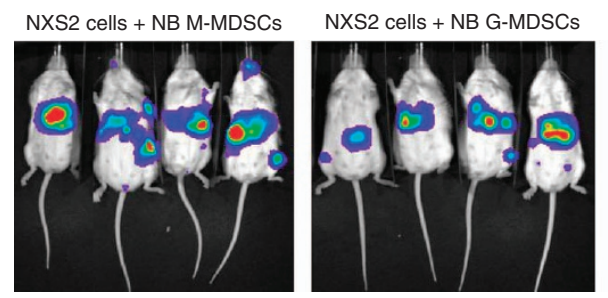

Luminescence

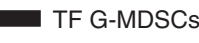

$\square$ TF M-MDSCs

$\square$ NB G-MDSCs

$\square$ NB M-MDSCs

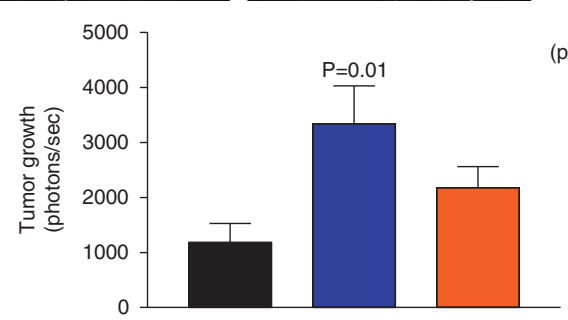

Figure 3 Mechanisms of suppressive activity of M-MDSCs and G-MDSCs in NB-bearing mice. M-MDSCs and G-MDSCs were isolated from the spleen of TF and NB tumor-bearing (NB) mice using the Murine Myeloid Derived Suppressor Cells Isolation Kit. Panel a shows ARG-1 expression in M-MDSCs cells by fluorescence microscopy. Original magnification $\times 20$. Panel $\mathbf{b}$ shows the percentage of ARG-1+ M-MDSCs and G-MDSCs. Data are expressed as mean value of ARG-1 ${ }^{+}$cells counted in 10 fields/ slide. $P$-values were calculated using unpaired $t$-test with Welch's correction. Panel $\mathbf{c}$ shows the level of ROS of M-MDSCs and G-MDSCs labelled with the oxidation-sensitive dye DCFDA. Results are expressed as the mean fluorescent intensity \pm S.D. from three different experiments performed. Panel $\mathbf{d}$ shows the level of TGF- $\beta 1$ produced by M-MDSCs and G-MDSCs as assessed by ELISA. Conditioned media from triplicate cultures were tested in duplicate. Data are expressed as mean value \pm S.D. P-value was calculated using unpaired t-test with Welch's correction. Panel e shows four representative animals i.v. inoculated with NXS2 transfected with luciferase (NXS2-LUC) in combination with M-MDSCs and G-MDSCs $\left(1: 1 ; 2 \times 10^{5}\right.$ cells/mouse) and imaged by bioluminescence 26 days after tumor cell inoculum. Tumor volume is expressed as mean luminescence value \pm S.D. $P$-value was calculated using unpaired $t$-test with Welch's correction

P2X7R is expressed and functional in G- and M-MDSC subsets in NB-bearing host. Previous studies have shown that the P2X7R is a main trigger for ROS and cytokine secretion in mononuclear phagocytes. ${ }^{25}$

Gene and protein expression of P2X7R was investigated in NB and TF G-MDSCs and M-MDSCs.

Figure $4 a$ shows that both NB G-MDSCs and M-MDSCs express P2X7R mRNA. Immunofluorescence analysis of P2X7R expression in G-MDSCs and M-MDSCs revealed a predominantly cytosolic, diffuse, staining in both MDSC subsets (Figure 4b). Interestingly, NB M-MDSCs also showed a clear and specific patchy P2X7R fluorescence on the plasma membrane (Figure 4b), that was never detected in TF G-MDSCs and M-MDSCs, or in NB G-MDSCs. These results suggest an enhanced and specific plasma membrane localization of the P2X7R in M-MDSCs isolated from NB-bearing mice.

P2X7R activation as ion channel has been shown to promote the release of different pro-inflammatory cytokines. ${ }^{20,26}$ In order to investigate whether stimulation of P2X7R induced cytokines release, conditioned media from TF and NB M-MDSCs or G-MDSCs, cultured in presence or absence of $100 \mu \mathrm{M}$ of P2X7R agonist benzoyl-ATP (BzATP), were evaluated for the secretion of cytokines, chemokines and growth factors by a magnetic bead-based assay. Figure $4 \mathrm{C}$ shows that CCL2 was released to a higher level from BzATP-treated NB M-MDSCs compared with the untreated TF M-MDSCs, suggesting that P2X7R activation is involved in the induction of CCL2 by M-MDSCs isolated from tumor-bearing mice. 
Table 1 Cytokines and chemokines secreted by G-MDSCs and M-MDSCs isolated from TF and NB-bearing mice

\begin{tabular}{|c|c|c|c|c|}
\hline & TF G-MDSCs & TF M-MDSCs & NB G-MDSCs & NB M-MDSCs \\
\hline IL-1 $\alpha$ & $1 \pm 0.18$ & $1.18 \pm 0.18$ & $0.7 \pm 0.1$ & $1 \pm 0.12$ \\
\hline IL-1 $\beta$ & $67 \pm 1.4$ & $76.8 \pm 1.5$ & $84 \pm 3$ & $102 \pm 11$ \\
\hline IL-2 & $6 \pm 0.8$ & $6.3 \pm 0.8$ & $4.8 \pm 0.5$ & $6.5 \pm 0.6$ \\
\hline IL-3 & $0.23 \pm 0.01$ & $0.24 \pm 0.01$ & $0.23 \pm 0.01$ & $0.22 \pm 0.01$ \\
\hline IL-4 & - & - & - & - \\
\hline IL-5 & $0.54 \pm 0.03$ & $0.64 \pm 0.1$ & $0.3 \pm 0.01$ & - \\
\hline IL-6 & - & - & - & - \\
\hline IL-9 & - & - & - & - \\
\hline IL-10 & $4.1 \pm 0.2$ & $4.4 \pm 0.4$ & $3 \pm 0.7$ & $3.9 \pm 0.3$ \\
\hline IL-12 (p40) & - & - & - & - \\
\hline IL-12 (p70) & $4.6 \pm 0.2$ & $5.5 \pm 0.7$ & $5.4 \pm 1.2$ & $6 \pm 1.5$ \\
\hline IL-13 & $8 \pm 1.5$ & $10.3 \pm 0.75$ & - & $9.2 \pm 1.2$ \\
\hline IL-17 & - & - & - & - \\
\hline Eotaxin (CCL11) & $24 \pm 3.4$ & $23.3 \pm 4.2$ & $13.7 \pm 5$ & $18 \pm 0.5$ \\
\hline G-CSF & - & - & - & - \\
\hline GM-CSF & - & - & - & - \\
\hline IFN- $\gamma$ & $0.5 \pm 0.3$ & $0.4 \pm 0.03$ & $0.54 \pm 0.05$ & $0.46 \pm 0.03$ \\
\hline $\mathrm{KC}(\mathrm{CXCL} 1)$ & - & - & - & - \\
\hline MCP-1 (CCL2) & $25.5 \pm 0.4$ & $24.2 \pm 0.8$ & $17.4 \pm 1.8$ & $16.5 \pm 0.6$ \\
\hline MIP-1 $\propto$ (CCL3) & $1.7 \pm 0.2$ & $2.5 \pm 0.2$ & $0.35 \pm 0.1$ & $1.8 \pm 0.6$ \\
\hline MIP-1 $\beta$ (CLL4) & $1.9 \pm 0.6$ & $2.5 \pm 1$ & $1.3 \pm 0.3$ & $2.9 \pm 0.7$ \\
\hline RANTES (CLL5) & $0.8 \pm 0.05$ & $0.66 \pm 0.03$ & $0.1 \pm 0.06$ & $0.5 \pm 0.09$ \\
\hline TNF- $\alpha$ & $7.8 \pm 0.8$ & $7.9 \pm 0.8$ & $6.3 \pm 0.7$ & $6.4 \pm 1.3$ \\
\hline
\end{tabular}

Conditioned media from triplicate cultures were assayed in triplicate. Values are represented as mean \pm S.D. and expressed in pg/ml. The data not represented were undetectable

a

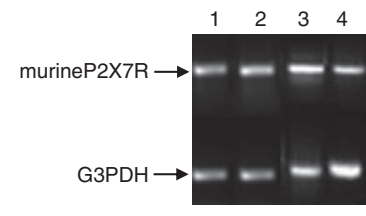

1) TF G-MDSCs

2) $T F M-M D S C s$

3) NB G-MDSCs

4) NB M-MDSCs

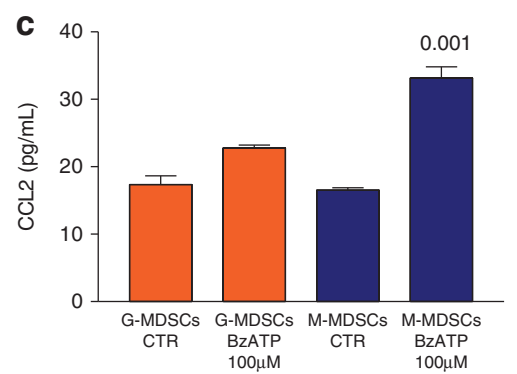

b
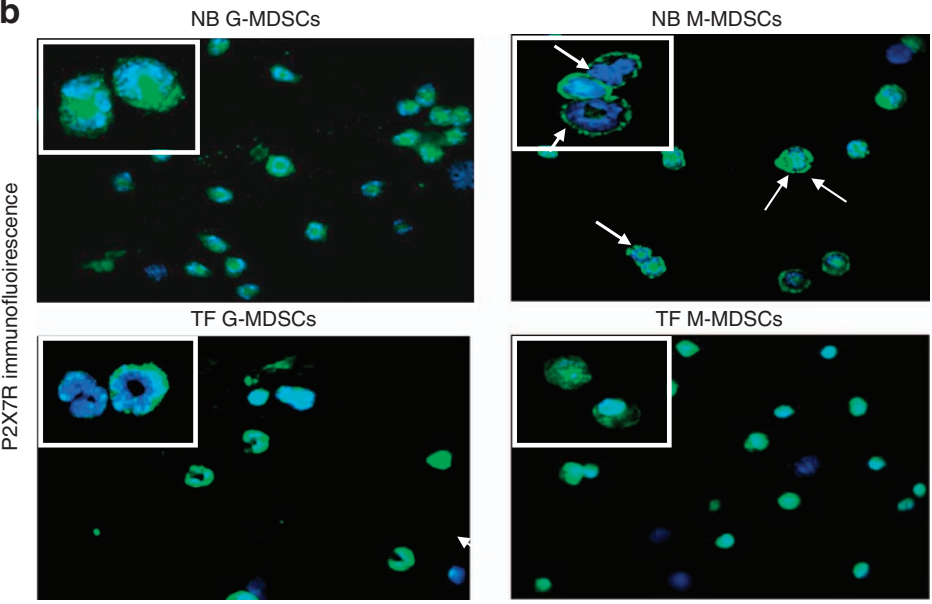

TF M-MDSCs

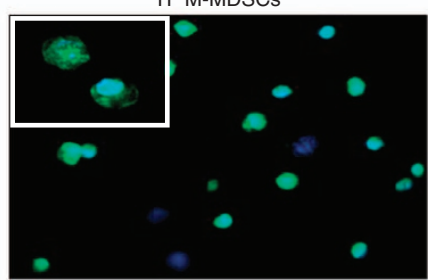

Figure 4 P2X7R expression in M-MDSCs and G-MDSCs in NB-bearing mice. Panel a shows the expression of murine P2X7R mRNA in TF and NB tumor-bearing (NB) M-MDSCs and G-MDSCs. RT-PCR was performed as described in Materials and Methods. GA3PDH amplification was used as positive control. Panel b shows P2X7R expression and localization in M-MDSCs and G-MDSCs by fluorescence microscopy. White arrows indicate P2X7R localization on the plasma membrane. Original magnification $\times 40$, inset panels $\times 100$. Panel $c$ shows basal and BzATP-stimulated CCL2 release by NB M-MDSCs

We next investigated whether the P2X7R of G-MDSCs and M-MDSCs showed the same functional responses of the canonical P2X7R expressed by other inflammatory cells. One of the earliest changes occurring after P2X7R activation is the collapse of plasma membrane potential due to $\mathrm{Na}^{+}$ influx. As shown in Figures $5 a$ and b, BzATP caused a large plasma membrane depolarization in both MDSC subsets. Interestingly, P2X7R-dependent plasma membrane depolarization was much larger in NB M-MDSCs than in TF M-MDSCs or G-MDSCs, whether from NB or TF mice (Figure $5 b$ ). Changes in fluorescence were fully abrogated by the P2X7R blocker oxidized ATP (oATP) (Figures 5a and b). 
a

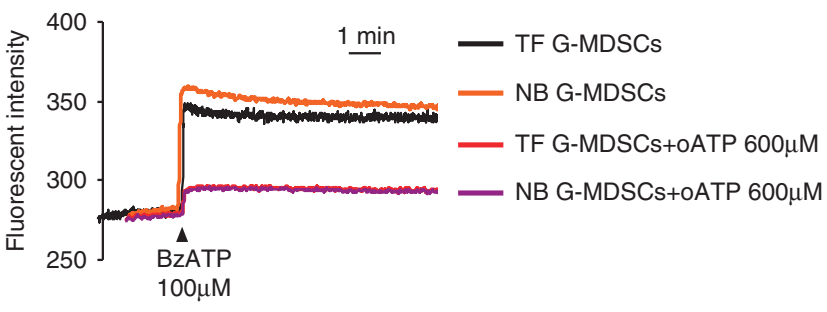

b

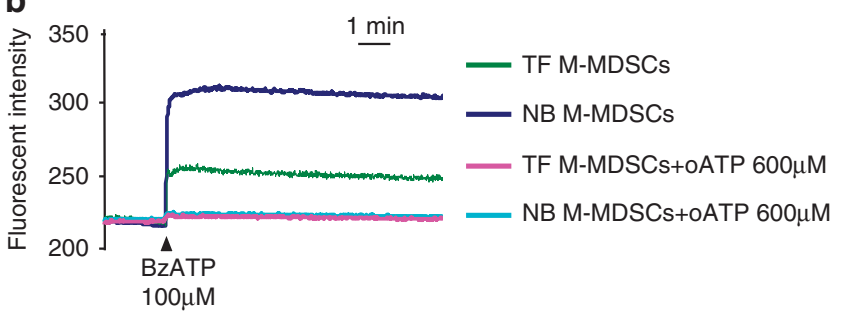

C

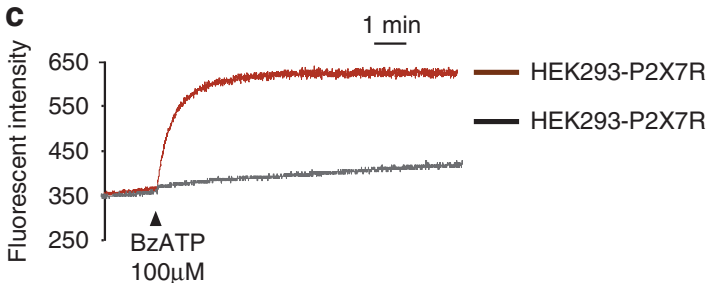

d
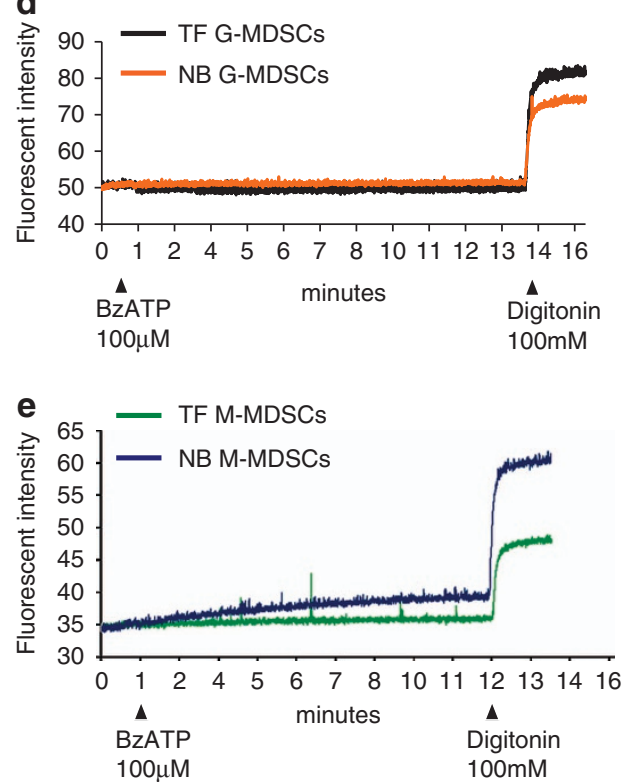

Figure 5 P2X7R-associated plasma membrane permeability changes in M-MDSCs and G-MDSCs from NB-bearing mice. Panels a and c show BzATP-mediated induction of plasma membrane depolarization in $\mathrm{Ca}^{2+}$-containing medium. Changes in plasma membrane potential were measured with bisoxonol as described in Materials and Methods. One representative experiment out of three performed with similar results is shown. Panel a shows the tracers of TF G-MDSCs (black trace), NB G-MDSCs (orange trace), TF G-MDSCs (red trace) and NB G-MDSCs (purple trace) pre-treated with OATP. Panel b shows the tracer of TF M-MDSCs (green trace), NB M-MDSCs (blue trace), TF M-MDSCs (pink trace) and NB M-MDSCs (cyan trace) pre-treated with oATP. Panel c shows the tracers of HEK293-P2X7R (brown trace) and HEK293-Mock (gray trace) cells used as positive and negative control respectively. Panels $\mathbf{d}$ and $\mathbf{e}$ show Bz-ATP-mediated induction of EtBr uptake. Panel $\mathbf{d}$ shows the tracers of TF G-MDSCs (black trace) and NB G-MDSCs (orange trace); panel e shows the tracers of TF M-MDSCs (green trace) and NB M-MDSCs (blue trace). One representative experiment out of three performed with similar results is shown

Figure $5 \mathrm{c}$ shows plasma membrane potential collapse of HEK293-P2X7R or HEH293-mock, used as positive and negative controls, respectively.

The hallmark of P2X7R activation is an ATP-dependent permeabilization of the plasma membrane to large molecules including ethidium bromide (EtBr). ${ }^{27}$ As shown in Figure $5 d$, stimulation with BzATP of TF M-MDSCs and G-MDSCs triggered no $\mathrm{EtBr}$ uptake. On the contrary, NB M-MDSCs underwent a small but clear $\mathrm{EtBr}$ uptake (Figure 5e), whereas NB G-MDSCs failed consistently to take up the dye (Figure $5 d$ ). This implies that P2X7R is functional as a pore only in M-MDSCs.

P2X7R expression and function in mouse MDSC lines. To confirm P2X7R functions in an independent mouse MDSC model, we took advantage of MSC-1 and MSC-2 cells, two MSDC lines generated in our laboratories. ${ }^{28}$ As shown in Figures $6 a$ and $b$, both MSC-1 and MSC-2 express P2X7R, the MSC-2 line to a substantially higher level than MSC-1. The P2X7R is fully functional as both lines show a large intracellular $\left[\mathrm{Ca}^{2+}\right]_{\mathrm{i}}$ increase in response to BzATP (Figures $6 \mathrm{c}-\mathrm{f}$ ). It is worth of notice that the $\left[\mathrm{Ca}^{2+}\right]_{\mathrm{i}}$ rise was over 10 times larger in the MSC-2 than in the MSC-1 lines, and was mainly due to influx from the extracellular space as it was almost entirely abrogated by chelation of extracellular $\mathrm{Ca}^{2+}$ (not shown). In the MSC-1 line, the BzATP dose-dependency curve was biphasic, witnessing the activation of at least two P2R subtypes: one with higher affinity, responsible for the $\left[\mathrm{Ca}^{2+}\right]_{i}$ increase at lower agonist concentrations, and another with lower affinity, responsible for the $\left[\mathrm{Ca}^{2+}\right]_{i}$ increase at higher agonist concentrations. ${ }^{29}$ The higher affinity response might be due to expression of a P2X7R splice variant, or alternatively to stimulation of another P2R subtype. BzATP is also reported to be active at the P2Y13R and there is electrophysiological indication that it might also be an agonist at P2X1, P2X2 and P2X3. ${ }^{30}$ Figures $6 \mathrm{~g}$ and $\mathrm{h}$ show that BzATP caused a massive uptake of EtBr. As shown by the dose-response curve (Figures 6h-j), also for EtBr uptake, MSC-2 showed a larger response than MSC-1. Furthermore, in agreement with the $\mathrm{Ca}^{2+}$ dosedependency, the MSC-1 EtBr uptake curve also was biphasic, thus reinforcing the suggestion that MSC-1 cells might express at least two P2X7R splice variants with different affinities, or an additional P2R subtype coupled to plasma membrane permeabilization.

In myelomonocytic cells P2X7R is well known to be coupled to inflammasome activation and $\mathrm{IL}-1 \beta$ release. ${ }^{31}$ To check 

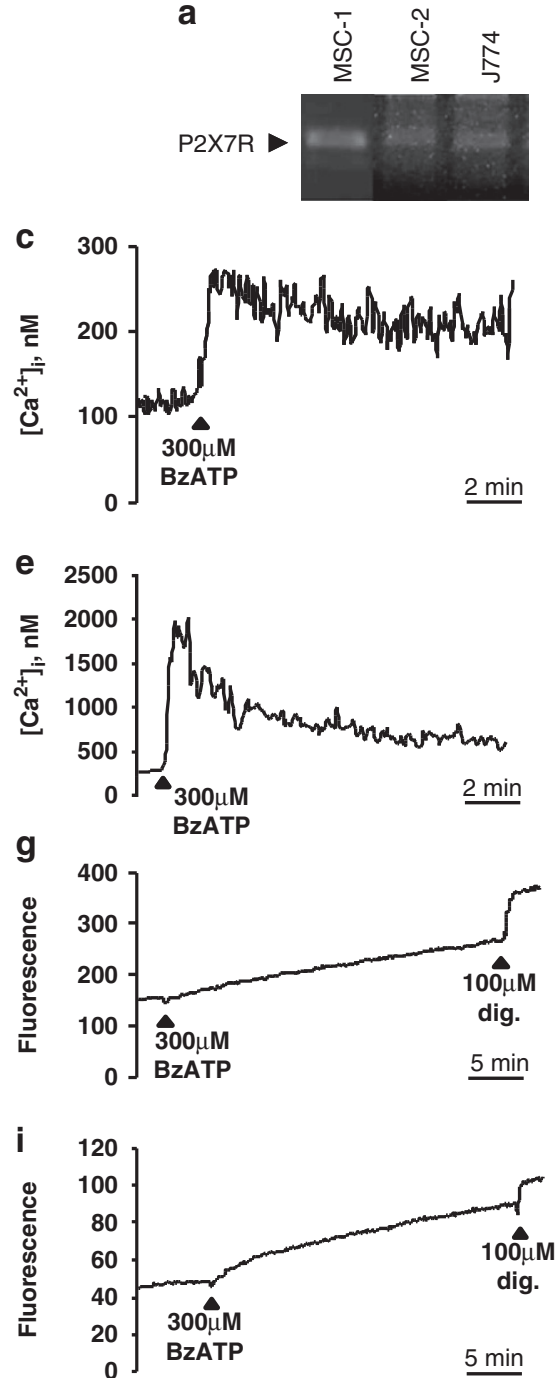

b

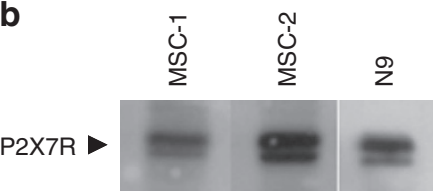

d
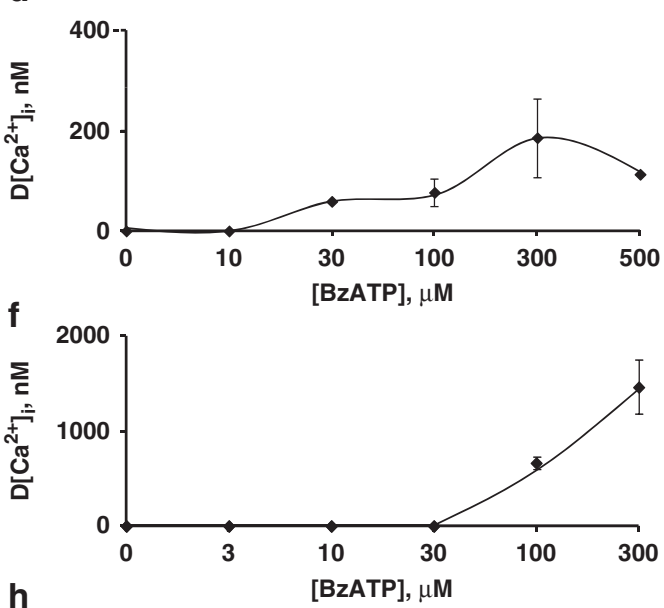

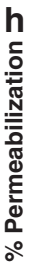

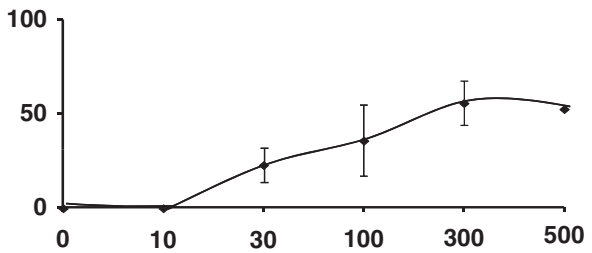

[BzATP], $\mu \mathrm{M}$

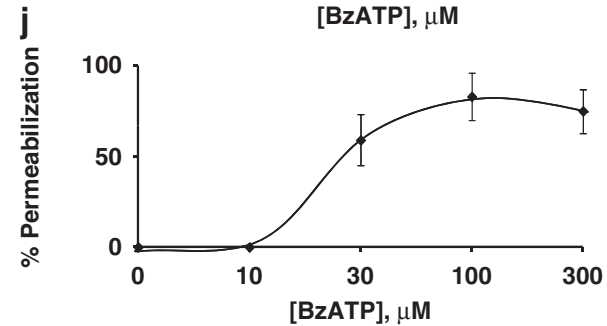

Figure 6 MSC-1 and MSC-2 express a functional P2X7R. Panel $\mathbf{a}$ and $\mathbf{b}$ show the expression of P2X7R mRNA and protein in MSC-1 and MSC-2 lines (positive controls: N9 microglia and J774 macrophages). Panels c-f show $\left.\left[\mathrm{Ca}^{2+}\right)\right]$ increases and BzATP dose dependency in MSC-1 (c and $\left.\mathbf{d}\right)$ and MSC-2 (Panels e and f) lines. Panels $\mathbf{g}-\mathbf{j}$ show EtBr uptake and BzATP dose dependency in MSC-1 ( $\mathbf{g}$ and $\mathbf{h}$ ) and MSC-2 (i and $\mathbf{j})$ lines

whether this is also the case for MSC-1 and MSC-2 lines, these cells were primed with lipopolysaccharides (LPS) for $4 \mathrm{~h}$, followed by BzATP challenge. As shown in Figures $7 a$ and $b$, P2X7R stimulation caused IL-1 $\beta$ release. Cytokine release was minimal, in MSC-1, and substantially larger in MSC-2. In addition, P2X7R stimulation triggered a significant induction of ARG-1 expression (Figures 7c and d), TGF- $\beta$ release (Figures $7 e$ and $f$ ) and ROS secretion (Figures $7 \mathrm{~g}$ and $\mathrm{h}$ ) from both MSC-1 and MSC-2 lines.

It is generally agreed that prolonged openings of the P2X7R pore is inevitably coupled to cell death. ${ }^{27}$ We tested the effect of high ATP or BzATP concentrations in MSC-1 and MSC-2 lines by monitoring release of the cytoplasmic marker lactate dehydrogenase (LDH). As shown in Figures $7 i$ and $j$, even after a prolonged exposure ( $8 \mathrm{~h}$ ) to $3 \mathrm{mM}$ ATP very little LDH release could be detected, showing that $\mathrm{P} 2 \mathrm{X} 7 \mathrm{R}$ pore opening was uncoupled from cytotoxicity.

\section{Discussion}

Release of ATP from cancer cells may contribute to in vivo tumor growth through P2R-mediated stimulation of cell proliferation $^{32}$ and angiogenesis. ${ }^{33}$ In the P2XR subfamily, the P2X7R has recently attracted hot interest due to its participation in inflammasome activation, cytokine release and stimulation of cell growth and apoptosis. The apparently mutually exclusive responses triggered by P2X7R activation likely rely on the two different activations states that P2X7R may have depending on the level of activation. Upon transient activation, the P2X7R behaves as a cation-selective channel 
a

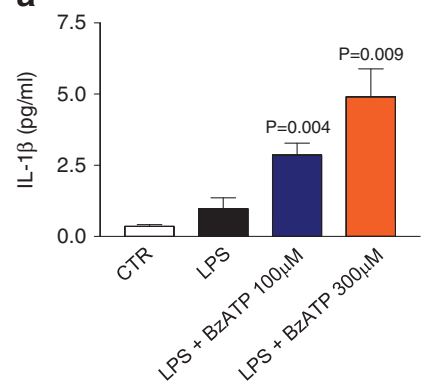

e

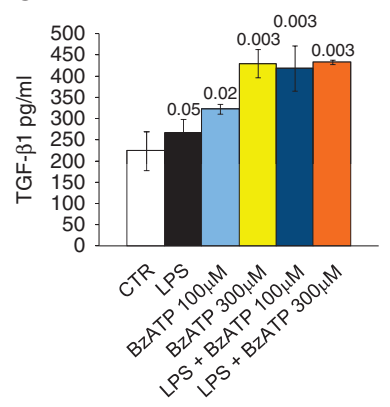

b

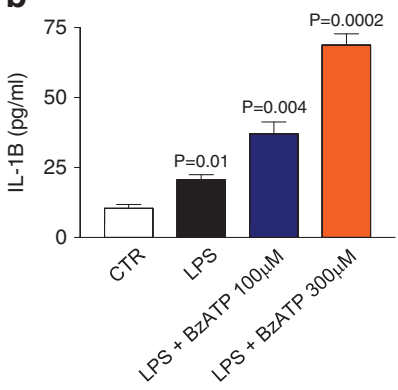

f

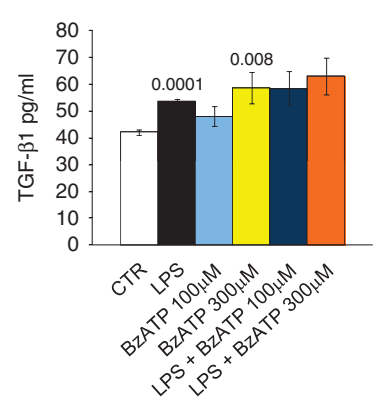

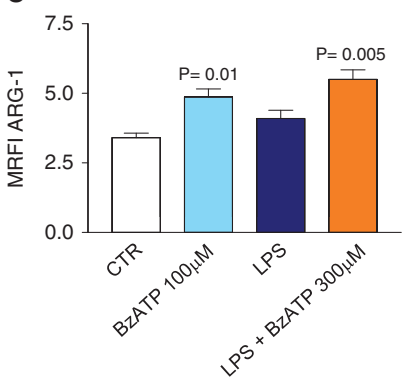

g

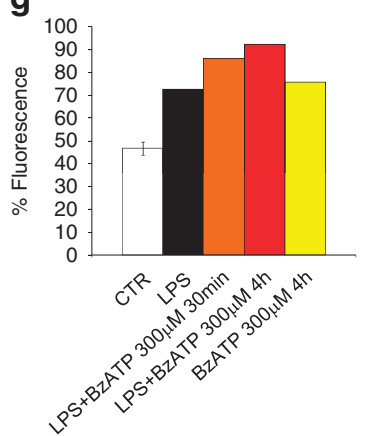

d

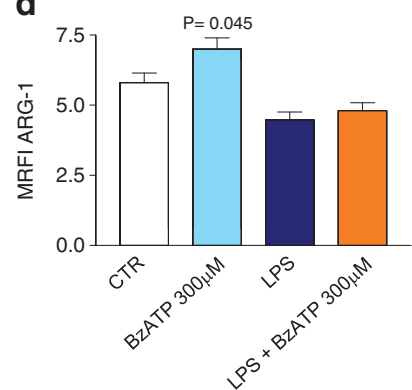

h

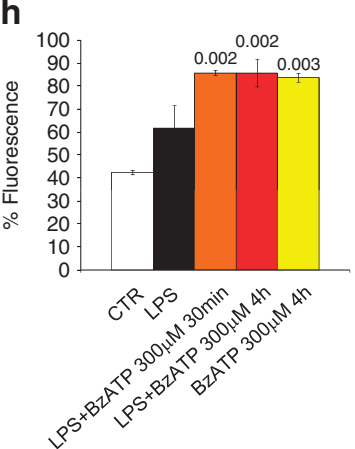

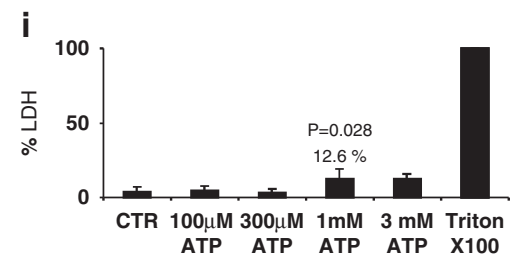

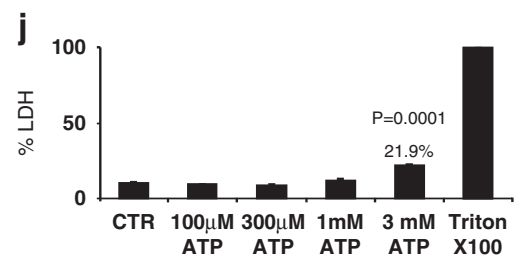

Figure 7 P2X7R-dependent IL-1 $\beta$ secretion, ARG-1 expression and LDH release from MSC-1 and MSC-2 lines. For IL-1 $\beta$ release (panels a and $\mathbf{b}$ ), cell lines were primed for $4 \mathrm{~h}$ with $1 \mu \mathrm{g} / \mathrm{ml}$ LPS and then stimulated for 30 min with BzATP. Cell-free supernatants were assayed for IL-1 $\beta$ concentration. For ARG-1 expression (panels $\mathbf{c}$ and d), TGF- $\beta 1$ secretion (panels e and f) and ROS production (panels $\mathbf{g}$ and $\mathrm{h}$ ), the cells were primed with $1 \mu \mathrm{g} / \mathrm{ml} \mathrm{LPS}$ for $4 \mathrm{~h}$, followed by stimulation with 100 or $300 \mu \mathrm{M} \mathrm{BzATP}$ for 30 min and $4 \mathrm{~h} \mathrm{BzATP}$ stimulations were performed also without the priming with LPS. For LDH release (panels $\mathrm{i}$ and j), cells were incubated at $37^{\circ} \mathrm{C}$ for $8 \mathrm{~h}$ in the presence of increasing ATP concentrations. Enzyme activity is expressed as \% of total activity released by Triton X-100

permeable to $\mathrm{Na}^{+}, \mathrm{K}^{+}$and $\mathrm{Ca}^{2+}$. On the contrary, sustained activation promotes a characteristic channel-to-pore transition that drives formation of a non-selective pore permeable to aqueous solutes. ${ }^{34}$ This latter event triggers cell death, via apoptosis or necrosis. ${ }^{35,36}$

In addition to its well known cytotoxic effect, ${ }^{16,35}$ P2X7R has been recently found to induce NALRP3 inflammasome activation and IL- $1 \beta$ release, as well as stimulation of cell proliferation. ${ }^{14,17,19,20}$ This latter effect is most striking in cells cultured under limited nutrient supply, suggesting that P2X7R might play a role in sustaining cancer growth and survival. ${ }^{14,17}$ In line with this hypothesis, P2X7R is over-expressed in several human malignancies including NB, a pediatric tumor with grim prognosis in its metastatic presentation at diagnosis. ${ }^{15,37-39}$ In particular, we previously reported that P2X7R is expressed and functional in primary NB cells, where it supports proliferation in a substance-P dependent manner. ${ }^{15}$ Furthermore, direct in vivo evidence that P2X7R promotes tumor growth was provided by a recent report showing that P2X7R transfection into human HEK-293 fibroblasts or mouse CT-26 colon carcinoma cell lines enhances tumor engraftment, accelerates in vivo growth rate, stimulates the rate of proliferation, angiogenesis and reduces apoptosis. ${ }^{40}$

Extracellular ATP is generally considered the prototypical danger signal, as it accumulates at inflammatory sites and within the tumor interstitium at concentrations that may reach the hundred micromolar range. On the contrary, ATP is almost undetectable in the interstitium of healthy tissues. ${ }^{11,41}$ Extracellular ATP is released into the tumor microenvironment by cancer cells and infiltrating inflammatory cells through different mechanisms including granule exocytosis, plasma membrane channels or lysis. ${ }^{5}$ Moreover, certain chemotherapeutic agents can induce antitumor immune responses through their ability to trigger ATP release by tumor cells. ${ }^{21,42}$ Once released into the extracellular milieu, ATP interacts with P2X7R expressed by DCs to stimulate release of IL- $1 \beta$, which in turn has been suggested to increase $\mathrm{CD}^{+}$and $\mathrm{CD8}{ }^{+}{ }^{+}$-mediated antitumor responses. ${ }^{21}$

A breakthrough in in vivo ATP studies has been the development of the pmeLUC probe. This probe can be transfected into reporter or tumor cells, that can be then inoculated into experimental animal models to monitor by BLI 
changes in the extracellular ATP concentration at inflammatory or tumor sites. ${ }^{41,43}$ The pmeLUC probe allows continuous monitoring of the extracellular ATP concentration in the very same animals for an extended length of time. Using this strategy, we show here that levels of extracellular ATP increase with time in NXS2-pmeLUC NB tumors, thus paralleling tumor progression and metastasis dissemination. In this respect, hepatic growth of melanoma and colon metastatic tumors was strongly inhibited in CD39 null mice due to the decreased production of Ado by CD39 ${ }^{+}$Treg. $^{44}$ ATP levels in the tumor interstitium are striking and never observed in healthy tissues, thus we wondered whether this nucleotide might have a role in determining the peculiar functional features of tumor microenvironment, notably its immunosuppressive properties. MDSCs are the prototypic immunosuppressive cell subset isolated from NB-bearing mice. MDSCs suppress adaptive and innate immunity ${ }^{45}$ by several mechanisms including (i) inhibition of antigen-specific and non-specific T-cell activation through the production of ARG-1, and ROS, the nitration of the T-cell receptor, and cysteine deprivation, ${ }^{46,47}$ (ii) induction of M2 macrophages that contribute to tumor progression and invasion, ${ }^{48,49}$ (iii) stimulation of Treg expansion ${ }^{50,51}$ and (iv) repression of NK cytotoxicity. ${ }^{52}$

MDSCs isolated from the spleen of tumor-bearing mice express two specific markers, that is, CD11b and Gr-1. ${ }^{53}$ In addition, on the basis of $\mathrm{Gr}-1$ staining intensity, two MDSC subsets can be identified. Gr-1 ${ }^{\text {high }}$ cells express $\mathrm{Gr}-1$ at high intensity and are prevalently constituted by granulocytes (G-MDSC); in contrast, Gr-1 ${ }^{\text {low }}$ cells express Gr-1 with low intensity and are mainly comprised of monocytes (M-MDSC). ${ }^{24,54,55}$

In most tumor models, the G-MDSC subset predominates, representing $70-80 \%$ of tumor-derived MDSCs. ${ }^{55}$ G-MDSCs were found to produce high levels of ROS and low levels of nitric oxide (NO), due to activation of Signal Transducer and Activator of Transcription (STAT)3 and NADPH oxidase, whereas the M-MDSC subset produced high levels of $\mathrm{NO}$ via STAT1 and inducible NO synthase activation. ${ }^{45}$

In agreement with a recent study showing the presence of CD11 ${ }^{+} \mathrm{Gr}-1^{+}$MDSCs in the spleen, PB and BM of Neuro-2a NB-bearing mice, ${ }^{23}$ we found that $\mathrm{CD} 11 \mathrm{~b}^{+} \mathrm{Gr}-1^{+}$cells are enriched in the spleen and PB of NXS2 NB-bearing mice compared with TF animals.

Moreover, NB M-MDSCs expressed higher levels of ARG-1, and produced higher amounts of ROS and TGF- $\beta 1$ in comparison with NB G-MDSCs. These findings suggest that MDSCs may be responsible for potent immunosuppressive functions in the NB microenvironment as ARG-1, ROS and TGF- $\beta 1$ are the major mediators of MDSC-driven immunosuppression. Functionality of immunosuppressionimplicated machinery may be also modulated by differential nutritional and bioenergetic MDSC behaviors. In this respect, a bioenergetic evaluation of MSC-1 cell line exhibited two distinct bioenergetic steady states that coincided with the exponential and stationary growth phases and were defined by specific concentrations of intracellular nucleotides, that is, ATP, ADP, AMP, CTP, GTP and UTP. ${ }^{56}$

Noteworthy, we found that the size of tumors generated by co-inoculation of NB cells and M-MDSCs was higher compared with that of control tumors (only NB cells) and tumors developed by co-injection of NB cells and G-MDSCs.

In line with our results, a recent study demonstrated that in different tumor models the in vitro immunosuppressive activity of MDSCs was inversely related to $\mathrm{Gr}-1$ marker expression. ${ }^{24}$

Our study provides the first evidence that ATP modulates MDSC responses via a P2X7R dependent mechanism. Quite interestingly, P2X7R was expressed to about the same level by M-MDCS and G-MDSC subsets isolated from the spleen of NB-bearing mice or TF animals, but the subcellular location was quite different since in M-MDSCs from NB tumor-bearing mice P2X7R was clearly expressed on the plasma membrane, whereas in G-MDSCs from tumor-bearing mice and in G-MDSCs and M-MDSCs from TF animals it was mainly localized either in the cytosol or in the nucleus. This sub-cellular location suggests that P2X7R may be more functional in NB M-MDSCs compared with the other Gr-1 subsets. In addition, enhanced functionality of P2X7R in NB M-MDSCs may be due to significantly higher ROS production by the latter cells in comparison with other MDSC Gr-1 subsets (see Figure 3c). ROS may be implicated in enhancing P2X7R potency on MDSCs themselves by an autocrine loop and on a $\mathrm{P} 2 \times 7 \mathrm{R}^{+}$adjacent cells in a paracrine manner. In this respect, a recent study demonstrated that mitochondria superoxide enhanced the potency of ATP/P2X7R-mediated CD62L downregulation on CD4 ${ }^{+}$T lymphocytes. ${ }^{57}$

P2X7R functionality on MDSC immunosuppression in tumor-bearing animals is under investigation.

ATP stimulation of P2X7R triggers release of several cytokines and growth factors. Here we show that P2X7R stimulation triggered CCL2 secretion from NB M-MDSCs but not from TF M-MDSC and G-MDSCs.

CCL2 is a chemokine with tumor-promoting effects including increased recruitment of macrophages to the tumor site, promotion of angiogenesis, invasion and metastasis. ${ }^{58}$ Interestingly, CCL2 has been shown to attract CCR2 ${ }^{+}$iNKT cells to $M Y C N$ non-amplified NB primary tumors, leading to development of anti-tumor immune responses. ${ }^{59}$ Furthermore, CCL2 that has undergone nitration in the tumor microenvironment loses the ability to attract effector $\mathrm{T}$ cells, while retaining that of recruiting MDSCs expressing the CCR2 at high level. ${ }^{60}$

The P2X7R is also expressed to a high level in the two myeloid cell lines with immunosuppressive activity MSC-1 and MSC-2. Here, its stimulation triggers release of IL-1 $\beta$, ROS, TGF $\beta 1$ and ARG-1 upregulation. High P2X7R expression by cells, such as the MDSCs, which are exposed to an ATP-rich environment (the tumor microenvironment) might seem paradoxical as this receptor is known to mediate a strong cytotoxic effect when activated. It is true that having P2X7R very low affinity for ATP ( $\mathrm{km}$ in the hundred micromolar range), conditions for its activation rarely if ever occur in healthy tissues, but it is now clear that on the contrary, extracellular ATP may reach levels well above the P2X7R km. Thus, how can MDSCs survive in such harsh conditions? The answer may reside in the uncoupling of P2X7R from cell death. This is not unprecedented as we have previously observed the same phenomenon in the human NB cells, where P2X7R uncoupling from death was due to lack of activation of caspase-3. Therefore, MDSCs might have 
adapted to live in an ATP-rich environment and be able to exploit P2X7R-dependent functional responses, but avoiding at the same time any deadly consequences.

On the basis of our results, we propose a scenario, whereby autocrine and paracrine loops mediated by the extracellular ATP released by NB cells may be envisaged. According to a autocrine/paracrine model, ATP released by NB cells interacts with P2X7R expressed by the same cells or adjacent tumor cells and drives tumor cell proliferation. ${ }^{15}$ In the paracrine loop, ATP secreted by NB cells interacts with P2X7R expressed by MDSCs and stimulate the release of CCL2, involved in tumor-associated macrophage, and iNKT recruitment. On the other hand, G-MDSCs, expressing high levels of CD73 ecto-5'-nucleotidase, may convert ATP into Ado, that in turn contributes to MDSC expansion and immunosuppressive activities through engagement of $A 2 B$ receptors. 61

In conclusion, we have shown for the first time that MDSCs from tumor-bearing mice express P2X7R which is functional and promotes release of immunosuppressive cytokines upon triggering with ATP.

\section{Material and Methods}

Cell lines. Murine NB NXS2 cell line $e^{62}$ and human embryonic kidney cells (HEK293) were cultured in Dulbecco's modified eagle medium (Euroclone, Milan, Italy) supplemented with L-glutamine, penicillin/streptomycin, non-essential amino acids and $10 \%$ fetal bovine serum (FBS) (Sigma, St. Louis, MO, USA) at $37^{\circ} \mathrm{C}$, in an atmosphere of $5 \% \mathrm{CO}_{2}$.

Murine NB NXS2 transfection with pmeLUC was carried out with Lipofectamine 2000 (Invitrogen, Monza, Italy) as previously described. ${ }^{63}$

Stable HEK293-P2X7R and HEK293-mock clones were transfected with an expression vector for the full length human P2X7R and an empty vector, respectively, as previously described. ${ }^{14}$ Transfected cells were cultured in the presence of $0.2 \mathrm{mg} / \mathrm{ml}$ G418 sulfate (Geneticin, Calbiochem, La Jolla, CA, USA). NXS2 cell lines were infected with retroviral luciferase vector NXS2 cell lines were infected with retroviral luciferase vector as follows. The retroviral luciferase vector was obtained by cloning the firefly luciferase gene, excised from the pGL3 control vector (Promega, Milan, Italy), into the retroviral pLXIN bicistronic vector (Clontech, Saint-Germain-en-Laye, France), to obtain PL-Luc-IN. Retroviruses were prepared by LipofectAMINE 2000 (Invitrogen) transient transfection of pL-Luc-IN into the helper virus free Phoenix-Ampho packaging cells (gift from Nolan Lab, Stanford University, Stanford, CA, USA). The retrovirus-containing supernatant was collected $48 \mathrm{~h}$ post-transfection and used to infect NXS2 cells. After $48 \mathrm{~h}$, the transduced cells were selected in the presence of $0.5 \mathrm{mg} / \mathrm{ml}$ of G418 (Calbiochem, Rome, Italy). The resulting cells were denominated NXS2-LUC, and presented phenotypic characteristics and in vitro growth properties virtually identical to the parental cells (data not shown).

G-MDSC, M-MDSC subsets isolated from spleen of naïve and NB-bearing mice, murine MSC-1 and MSC-2 cell lines ${ }^{28}$ were cultured in RPMI 1640 (Euroclone) supplemented with $100 \mathrm{IU} / \mathrm{ml}$ penicillin, $50 \mu \mathrm{g} / \mathrm{ml}$ streptomycin (all from Sigma-Aldrich, Milano, Italy) $1 \%$ L-glutamine, $1 \%$ sodium pyruvate (Euroclone) and $10 \%$ FBS superior (Biochrom, Cambridge, UK) at $37^{\circ} \mathrm{C}$, in an atmosphere of $5 \%$ $\mathrm{CO}_{2}$. Murine microglial $\mathrm{N} 9$ cell line (kindly provided by Dr. Paola Ricciardi-Castagnoli, University of Milano, Italy) were cultured in RPMI 1640 medium (PAA, Linz, Austria) supplemented with $2 \mathrm{mM}$ glutamine, 10\% heat-inactivated FCS (Life Technologies Ltd., Paisley, Scotland), $100 \mathrm{U} / \mathrm{ml}$ penicillin and $100 \mathrm{pg} / \mathrm{ml}$ streptomycin.

Mouse macrophage cell line (J774) were cultured in Dulbecco's modified eagle medium supplemented with $100 \mathrm{IU} / \mathrm{ml}$ penicillin, $50 \mu \mathrm{g} / \mathrm{ml}$ streptomycin (all from Sigma-Aldrich) 1\% L-glutamine and 10\% FBS (Sigma).

In vivo studies. All experiments involving animals were reviewed and approved by the licensing and ethical committee of the National Cancer Research Institute, Genoa, Italy, and by the Italian Ministry of Health. Mice were purchased from Harlan Laboratories (Harlan Italy, S. Pietro al Natisone, Italy) and housed under specific pathogen-free conditions.
Evaluation of extracellular ATP levels in NB microenvironment. Six-week-old female immunocompetent syngeneic $A / J$ mice $(n=5)$ were i.v. injected in the tail vein with pmeLUC-NXS2 cells $\left(2 \times 10^{5}\right.$ cells/mouse). BLI was performed evaluating the stably pmeLUC-transfected NB cell, by highly sensitive, cooled CCD camera mounted in a light-tight specimen box (IVIS; Xenogen, Waltham, MA, USA). Briefly, 10 min before every acquisition, animals were intraperitoneally injected with the substrate D-luciferin (Promega) and anesthetized with $1-3 \%$ isofluorane (Veterinaria Esteve, Alcazar De San Juan, Spain). Mice were then placed onto the warmed stage, inside the light-tight camera box, with continuous exposure to $1-2 \%$ isofluorane. BLI was performed after 7, 12, 19 and 26 days after tumor cell inoculum.

In some experiments, immunocompetent syngeneic A/J mice were i.v. coinjected with murine NB NXS2 cells transfected with luciferase (NXS2-Luc) and Gor M-MDSCs $\left(1: 1 ; 2 \times 10^{5}\right.$ cells/mouse). Body weight and general physical status of the animals were recorded daily, and mice were killed by cervical dislocation after being anesthetized with xilezine (Xilor $\%$, Bio98 Srl, Milan, Italy) when they showed signs of poor health, such as abdominal dilatation, dehydration or paraplegia. The animals were imaged 8, 14, 20 and 26 days after tumor cell inoculum by BLI.

Flow cytometric analysis. Single-cell suspension obtained from spleen, $\mathrm{BM}$ and $\mathrm{PB}$ isolated from NB-bearing and healthy animals were washed with PBS (Sigma), incubated with Fc blocking reagent (BD Biosciences, San Diego, CA, USA) and then stained for $20 \mathrm{~min}(\mathrm{~min})$ at $4^{\circ} \mathrm{C}$ with the relevant $A b$. The Abs used were: CD11b PerCP/Cy5.5 (BioLegend, London, UK), Ly-6G/Ly-6C (Gr-1) APC (BioLegend) and isotype-matched control monoclonal antibodies (Biolegend). After staining, samples were acquired with a Gallios cytometer (Beckman Coulter, Milan, Italy) and data were analyzed using Kaluza software (Beckman Coulter).

In some experiments, MSC-1 and MSC-2 cell lines were pretreated or not with LPS (Sigma) $(1 \mu \mathrm{g} / \mathrm{ml})$ for $4 \mathrm{~h}$ and then treated with BzATP $(100$ and $300 \mu \mathrm{M})$ for $30 \mathrm{~min}$. The cells were fixed with $2 \%$ paraformaldehyde at RT for $20 \mathrm{~min}$ and permeabilized with permeabilization buffer (PBS, $1 \%$ FBS, $0.1 \%$ saponin, Sigma). Then, cells $\left(5 \times 10^{5} /\right.$ tube) were incubated with anti-ARG-1 polyclonal Ab from Sigma and Santa Cruz Biotechnology (Heidelbergh, Germany) for 30 min at RT, washed twice with permeabilization buffer and incubated with FITC-conjugated $\mathrm{F}\left(a b^{\prime}\right)_{2}$ fragments of goat anti-rabbit IgG antibodies (Abcam, Cambridge, UK). After resuspension in staining buffer, cells were then analyzed by flow cytometry using a FACScan instrument (BD Biosciences, San Josè, CA, USA).

ROS detection. MSC-1 and MSC-2 were primed with $1 \mu \mathrm{g} / \mathrm{ml}$ LPS for $4 \mathrm{~h}$ at $37^{\circ} \mathrm{C}, 5 \% \mathrm{CO}_{2}$, followed by stimulation with $300 \mu \mathrm{M}$ BzATP for $30 \mathrm{~min}$. After stimulation, cells were detached and incubated with $10 \mu \mathrm{M}$ dichlorodihydrofluorescein diacetate (DCFDA) (Invitrogen) for $30 \mathrm{~min}$ at $37^{\circ} \mathrm{C}$. Cells were then analyzed using a Tali Image Cytometer (Life Technologies, Monza, Italy) at $458 \mathrm{~nm}$ excitation with a 520/525 nm emission filter. MSC-1 and MSC-2 were also incubated with $500 \mu \mathrm{M} \mathrm{H}_{2} \mathrm{O}_{2}$ (Sigma) for $4 \mathrm{~h}$ at $37^{\circ} \mathrm{C}$, absorbance of these samples was considered as $100 \%$. Alternatively, G-MDSC and M-MDSC subsets were incubated at $37^{\circ} \mathrm{C}$ in $1 \% \mathrm{FBS}$ in the presence of $2.5 \mu \mathrm{M}$ DCFDA for $30 \mathrm{~min}$ and evaluated by Gallios cytometer.

TGF- $\beta 1$ and NO secretion measurement. Supernatants from G- and M-MDSCs, MSC-1 and MSC-2 cell lines were collected after $48 \mathrm{~h}$-culture in 96-well plates $\left(2 \times 10^{5}\right.$ cells/well). TGF- $\beta 1$ concentration was determined by a Mouse TGF- $\beta 1$ Platinum ELISA (Bender MedSystem eBioscience, Vienna, Austria) according to the manufacturer's instructions. MSC-1 $\left(5 \times 10^{4}\right)$ and MSC-2 $\left(2 \times 10^{5}\right)$ were primed with $1 \mu \mathrm{g} / \mathrm{ml}$ LPS for $4 \mathrm{~h}$ at $37^{\circ} \mathrm{C}$, followed by stimulation with either 100 or $300 \mu \mathrm{M}$ BzATP for $30 \mathrm{~min}$. In some experiments, BzATP stimulations were performed without LPS priming. NO levels were measured with the Griess Reagent System (Molecular Probes, Invitrogen, Eugene, OR, USA) according to the manufacturer's instructions.

Reverse transcriptase polymerase chain reaction. Reverse transcription was carried out using specific primer sequences for mouse P2X7R (sense 5'-ATATCCACTTCCCCGGCCAC-3'; antisense 3'-TGCGCAGTCATGGCACCAT-5). The RNA samples (100 ng) were reversed transcribed using the ACCESS RT-PCR kit (Promega, Monza, Italy), with the following conditions: denaturation at $95^{\circ} \mathrm{C}$ for $2 \mathrm{~min}$ (one cycle) and reverse transcription at $48^{\circ} \mathrm{C}$ for $45 \mathrm{~s}$ (one cycle); 33 cycles of denaturation at $94^{\circ} \mathrm{C}$ for $45 \mathrm{~s}$, annealing at $56.5^{\circ} \mathrm{C}$ for $30 \mathrm{~s}$, extension at $68^{\circ} \mathrm{C}$ for $1 \mathrm{~min}$, followed by a final extension at $68^{\circ} \mathrm{C}$ for $4 \mathrm{~min}$. As control, we evaluated glyceraldehyde 3-phosphate dehydrogenase (GAPDH) amplification, 
using the following primers: forward $5^{\prime}$-CAAGGAGTAAGAAACCCTGAC-3'; reverse $3^{\prime}$-AATTGTGAGGGAGATGCTCAGT-5'. PCR products $(100 \mathrm{ng})$ were separated by agarose gel electrophoresis using an Agarose Electrophoresis Grade (Invitrogen) and then visualized by Gel Red staining. A 100-bp DNA Ladder (Fermentas, Thermo Scientific, Cornaredo, Italy) was used as a molecular weight marker. Specific primer sequences for mouse P2X7R were: sense $5^{\prime}-A$ TATCCACTTCCCCGGCCAC- $3^{\prime}$; antisense $3^{\prime}$-TGCGCAGTCATGGCACCAG-5'). PCR products were run on a $1.5 \%$ agarose gel containing $0.5 \mu \mathrm{g} / \mathrm{ml} \mathrm{EtBr}$ and photographed under UV light. The following bands were expected: P2X7 (171 bp) and -GAPDH- (177 bp).

Western blot analysis. MSC-1 and MSC-2 pellets were resuspended in sucrose saline containing benzamidine and PMSF (Sigma). A 7.5\% acrilamide gel was run by loading in each lane $30 \mu \mathrm{g}$ of protein solubilized in 0 solution (10\% w/v glycerol, $5 \%$ v/v 2-mercaptoethanol, $2.3 \%$ w/v SDS, $62.5 \mathrm{mM}$ Tris-Cl, $0.003 \%$ bromophenol blue). Western blotting was performed by transferring proteins onto a nitrocellulose membrane (Amersham Biosciences, Little Chalfont, UK). Blocking of non-specific binding sites was achieved by incubating the membrane with $10 \%$ skim-milk in TBS buffer (10 mM Tris-Cl, $150 \mathrm{mM} \mathrm{NaCl}, \mathrm{pH} 8.0$ ) for $1 \mathrm{~h}$. The primary anti-P2X7 antibody (Sigma) was used overnight at a dilution of 1:200 in TBS buffer containing $2 \% \mathrm{BSA}$. Antibody binding was visualized by the protein $\mathrm{A}$ peroxidase-linked process (GE Healthcare, Milan, Italy).

Cytosolic $\mathrm{Ca}^{2+}$ concentration measurement. Cells were loaded with the $\mathrm{Ca}^{2+}$ indicator fura-2/AM $(2 \mu \mathrm{M})$ (Molecular Probes, Leiden, The Netherlands) for $20 \mathrm{~min}$ at $37^{\circ} \mathrm{C}$ in a standard saline solution containing: $125 \mathrm{mM} \mathrm{NaCl}, 5 \mathrm{mM}$ $\mathrm{KCl}, 1 \mathrm{mM} \mathrm{MgSO}_{4}, 1 \mathrm{mM} \mathrm{NaH}_{2} \mathrm{PO}_{4}, 20 \mathrm{mM}$ HEPES, $5.5 \mathrm{mM}$ glucose, $5 \mathrm{mM}$ $\mathrm{NaHCO}_{3}, 1 \mathrm{mM} \mathrm{CaCl}$ and $250 \mu \mathrm{M}$ sulfinpyrazone (Sigma), pH 7.4. Cells $\left(1 \times 10^{6}\right)$ were stimulated with BzATP (Sigma) in a temperature-controlled magnetically stirred cuvette at $37^{\circ} \mathrm{C}$ and intracellular $\mathrm{Ca}^{2+}$ concentration $\left[\mathrm{Ca}^{2+}\right]_{\mathrm{i}}$ changes were measured with a Perkin Elmer fluorometer (Perkin Elmer Ltd., Beaconsfield, UK). The excitation was at $340-380 \mathrm{~nm}$, and emission at $510 \mathrm{~nm} . \mathrm{Ca}^{2+}$ concentration was calculated using the FLwinlab software (Perkin Elmer).

Immunofluorescence analysis. G- and M-MDSCs were centrifuged on polylisine slides, dried at RT and fixed in $2 \%$ paraformaldehyde in PBS $(\mathrm{pH} 7.4)$ for 20 min at RT. After washing with PBS, the slides were incubated with ammonium chloride $100 \mathrm{mM}$ for $20 \mathrm{~min}$ at $4 \mathrm{C}^{\circ}$, permeabilized with Triton X-100 (0.1\% in PBS) for $8 \mathrm{~min}$ at RT and blocked with BSA ( $2 \%$ in PBS) for 20 min at RT. Cells were then incubated for $1 \mathrm{~h}$ with anti-P2X7R and anti-ARG-1 Abs (Sigma Aldrich and Santa Cruz Biotechnology, respectively). Binding of primary antibodies was detected with fluorescein goat anti-rabbit IgG (Invitrogen). After rinsing, the slides were counterstained with DAPI (Vectashield mounting, Vector Laboratories, Orton Southgate, Peterborough, UK) and coverslipped. Digital images were acquired using a Nikon E-1000 fluorescence microscope (Nikon Instruments, Tokyo, Japan) equipped with appropriate filter sets and the Genikon imaging system software (Nikon Instruments).

Measurement of plasma membrane potential. P2X7R-dependent change in plasma membrane depolarization was measured with the fluorescent dye bis[11,3-diethylthiobarbiturate trimethineoxonal] (bisoxonol) (Molecular Probes), at the wavelength pair $560 / 580 \mathrm{~nm}$, as previously described. ${ }^{34}$ Briefly, $5 \times 10^{5} \mathrm{G}$ - or M-MDSCs were incubated at $37^{\circ} \mathrm{C}$ in a fluorimeter cuvette with magnetic stirring in the presence of bisoxonol $(200 \mathrm{nM})$ and stimulated by the addition of $100 \mu \mathrm{M}$ BzATP or left unchallenged (controls). Fluorescence analysis was performed at $560 \mathrm{~nm} / 580 \mathrm{~nm}$ in a PerkinElmer LS50 spectrofluorometer (PerkinElmer, Waltham, MA, USA) for $20 \mathrm{~min}$. In some experiments, cells were pre-treated for $2 \mathrm{~h}$ at $37^{\circ} \mathrm{C}$ with $600 \mu \mathrm{M}$ oATP (Sigma), a covalent P2X7R antagonist. HEK293-P2X7R and HEK293-mock cells were used as positive or negative controls, respectively.

Changes in plasma membrane permeability. P2X7R-dependent pore formation and increase in plasma membrane permeability were measured by monitoring $\mathrm{EtBr}$ uptake. Briefly, $5 \times 10^{5} \mathrm{G}$ - and M-MDSCs were incubated at $37^{\circ} \mathrm{C}$ in a $\mathrm{Ca}^{2+}$-free standard saline solution containing $20 \mu \mathrm{M} \mathrm{EtBr}$ in the presence or absence of $300 \mu \mathrm{M}$ BzATP (Sigma). Fluorescence was evaluated with a Gallios cytometer or in a magnetically stirred fluorometric cuvette, thermostatted at $37^{\circ} \mathrm{C}$. HEK293-P2X7R and HEK293-mock cells were used as positive and negative controls, respectively. Alternatively, in MSC-1 and MSC-2 cell lines, EtBr uptake was measured in a thermostatted $\left(37^{\circ} \mathrm{C}\right)$ PerkinElmer fluorimeter as described previously. ${ }^{63}$

Cell death assay. Cell death was monitored by LDH release. Briefly, MSC-1 $\left(1 \times 10^{5}\right)$ and MSC-2 $\left(5 \times 10^{5}\right)$ were incubated in culture medium in the presence of increasing ATP (Roche Diagnostics, Monza, Italy) concentrations for $8 \mathrm{~h}$. Supernatants were then collected and added to a solution containing, $0.63 \mathrm{mM}$

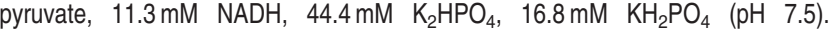
Absorbance was measured in a spectrofluorometer (Ultrospec 3000, Pharmacia Biotech, Milan, Italy) at a wavelength of $340 \mathrm{~nm}$. Cells were also lysed with $0.1 \%$ Triton X-100 (JT Baker, Milan, Italy) and cleared by centrifugation. Absorbance of these samples was considered as $100 \%$ of LDH release.

Chemokine, cytokine and growth factor assay. Multi-plex cytokine array analysis was performed using the Bio-plex protein multi-array system, based on the Luminex technology. Conditioned media from G-MDSC and M-MDSC subsets cultured in presence or absence of $100 \mu \mathrm{M}$ BzATP for $30 \mathrm{~min}$, were assayed by Bio-Plex Pro mouse cytokine 23-plex immunoassay (BIOCLARMA, Molecular Biotechnology Center, University of Turin, Italy), according to the recommendations of the manufacturer (Bio-Rad Laboratories, Milan, Italy). For IL-1 $\beta$ secretion MSC-1 $\left(5 \times 10^{4}\right)$ and MSC-2 $\left(2 \times 10^{5}\right)$ were seeded in polylisin-coated 24-well plates (Sigma Aldrich). Cells were primed with $1 \mu \mathrm{g} / \mathrm{ml}$ LPS (Sigma Aldrich) for $4 \mathrm{~h}$ at $37^{\circ} \mathrm{C}$, followed by stimulation with either 100 or $300 \mu \mathrm{M}$ BzATP for $30 \mathrm{~min}$. After stimulation, the whole medium $(300 \mu \mathrm{l})$ was collected and centrifuged at $160 \mathrm{~g}$ for $5 \mathrm{~min}$, followed by transfer of the supernatant to a fresh tube. Supernatants were stored at $-80^{\circ} \mathrm{C}$ and assayed with Mouse IL-1 $\beta$, Quantikine ELISA (RandD Systems, Abingdon, UK).

Statistical analysis. The statistical significance of differences between experimental and control groups was assessed by unpaired $t$-test with Welch's correction using GraphPad Prism 3.0 software (GraphPad Software, El Camino Real, San Diego, CA, USA).

\section{Conflict of Interest}

The authors declare no conflict of interest.

Acknowledgements. This study was supported by: AIRC, 'Cinque per mille dell'IRPEF - Finanziamento della ricerca sanitaria' (to VP), AIRC MFAG (to LR), AIRC (to FDV), the Ministry of Health 'Finanziamento Ricerca Corrente' (to VP) and 'Progetto di Ricerca Finalizzata 2008 G2IJ11000040001 (to VP), the Ministry of Education (FIRB n. RBAP11FXBC and PRIN n. 2009LMEEEH to FDV), the Ministry of Education (FIRB $n$. RBAP11FXBC_004 to VP). Giovanna Bianchi was a recipient of an FIRC fellowship and is now a recipient of a FIRB fellowship. We thank Dr. ssa Santina Bruzzone for helpful discussion and technical assistance.

1. Whiteside TL. The tumor microenvironment and its role in promoting tumor growth. Oncogene 2008; 27: 5904-5912.

2. Mantovani A, Sica A. Macrophages, innate immunity and cancer: balance, tolerance, and diversity. Curr Opin Immunol 2010; 22: 231-237.

3. Vesely MD, Kershaw MH, Schreiber RD, Smyth MJ. Natural innate and adaptive immunity to cancer. Annu Rev Immunol 2011; 29: 235-271.

4. Gabrilovich DI, Ostrand-Rosenberg S, Bronte V. Coordinated regulation of myeloid cells by tumours. Nat Rev Immunol 2012; 12: 253-268.

5. Di Virgilio F. Purines, purinergic receptors, and cancer. Cancer Res. 2012; 72: 5441-5447.

6. Kumar V. Adenosine as an endogenous immunoregulator in cancer pathogenesis: where to go? Purinergic Signal 2012; 9: 145-165

7. Stagg J, Smyth MJ. Extracellular adenosine triphosphate and adenosine in cancer. Oncogene 2010; 29: 5346-5358.

8. Ryzhov S, Novitskiy SV, Zaynagetdinov R, Goldstein AE, Carbone DP, Biaggioni I et al. Host $\mathrm{A}(2 \mathrm{~B})$ adenosine receptors promote carcinoma growth. Neoplasia 2008; 10: 987-995.

9. Adinolfi E, Callegari MG, Cirillo M, Pinton P, Giorgi C, Cavagna D et al. Expression of the $\mathrm{P} 2 \mathrm{X} 7$ receptor increases the $\mathrm{Ca} 2+$ content of the endoplasmic reticulum, activates NFATc1, and protects from apoptosis. J Biol Chem 2009; 284: 10120-10128.

10. Deaglio S, Dwyer KM, Gao W, Friedman D, Usheva A, Erat A et al. Adenosine generation catalyzed by $\mathrm{CD} 39$ and $\mathrm{CD} 73$ expressed on regulatory $\mathrm{T}$ cells mediates immune suppression. J Exp Med 2007; 204: 1257-1265

11. Ohta A, Gorelik E, Prasad SJ, Ronchese F, Lukashev D, Wong MK et al. A2A adenosine receptor protects tumors from antitumor T cells. Proc Natl Acad Sci USA 2006; 103 : 13132-13137. 
12. Di Virgilio F, Boeynaems JM, Robson SC. Extracellular nucleotides as negative modulators of immunity. Curr Opin Pharmacol 2009; 9: 507-513.

13. Di Virgilio F, Ferrari D, Adinolfi E. P2X(7): a growth-promoting receptor-implications for cancer. Purinergic Signal 2009; 5: 251-256.

14. Adinolfi E, Callegari MG, Ferrari D, Bolognesi C, Minelli M, Wieckowski MR et al. Basal activation of the P2X7 ATP receptor elevates mitochondrial calcium and potential, increases cellular ATP levels, and promotes serum-independent growth. Mol Biol Cell 2005; 16: 3260-3272.

15. Raffaghello L, Chiozzi P, Falzoni S, Di Virgilio F, Pistoia V. The P2X7 receptor sustains the growth of human neuroblastoma cells through a substance P-dependent mechanism. Cancer Res 2006; 66: 907-914.

16. Di Virgilio F, Chiozzi P, Falzoni S, Ferrari D, Sanz JM, Venketaraman V et al. Cytolytic P2X purinoceptors. Cell Death Differ 1998; 5: 191-199.

17. Baricordi OR, Melchiorri L, Adinolfi E, Falzoni S, Chiozzi P, Buell G et al. Increased proliferation rate of lymphoid cells transfected with the P2X(7) ATP receptor. J Biol Chem 1999; 274: 33206-33208.

18. Hanley PJ, Kronlage M, Kirschning C, del Rey A, Di Virgilio F, Leipziger J et al. Transient P2X7 receptor activation triggers macrophage death independent of Toll-like receptors 2 and 4, caspase-1, and pannexin-1 proteins. J Biol Chem 2012; 287: 10650-10663.

19. Zitvogel L, Kepp O, Galluzzi L, Kroemer G. Inflammasomes in carcinogenesis and anticancer immune responses. Nat Immunol 2012; 13: 343-351.

20. Ferrari D, Pizzirani C, Adinolfi E, Lemoli RM, Curti A, Idzko M et al. The P2X7 receptor: a key player in IL-1 processing and release. J Immunol 2006; 176: 3877-3883.

21. Ghiringhelli F, Apetoh $L$, Tesniere A, Aymeric $L, M a Y$, Ortiz $C$ et al. Activation of the NLRP3 inflammasome in dendritic cells induces IL-1beta-dependent adaptive immunity against tumors. Nat Med 2009; 15: 1170-1178.

22. Maris JM, Hogarty MD, Bagatell R, Cohn SL. Neuroblastoma. Lancet 2007; 369: 2106-2120.

23. Santilli G, Piotrowska I, Cantilena S, Chayka O, D'Alicarnasso M, Morgenstern DA et al. Polyphenol e enhances the antitumor immune response in neuroblastoma by inactivating myeloid suppressor cells. Clin Cancer Res 2013; 19: 1116-1125.

24. Dolcetti L, Peranzoni E, Ugel S, Marigo I, Fernandez Gomez A, Mesa C et al. Hierarchy of immunosuppressive strength among myeloid-derived suppressor cell subsets is determined by GM-CSF. Eur J Immunol 2010; 40: 22-35.

25. Rayah A, Kanellopoulos JM, Di Virgilio F. P2 receptors and immunity. Microbes Infect 2012; 14: 1254-1262.

26. Mehta VB, Hart J, Wewers MD. ATP-stimulated release of interleukin (IL)-1beta and IL-18 requires priming by lipopolysaccharide and is independent of caspase-1 cleavage. J Biol Chem 2001; 276: 3820-3826.

27. Di Virgilio F. The P2Z purinoceptor: an intriguing role in immunity, inflammation and cell death. Immunol Today 1995; 16: 524-528.

28. Apolloni E, Bronte V, Mazzoni A, Serafini P, Cabrelle A, Segal DM et al. Immortalized myeloid suppressor cells trigger apoptosis in antigen-activated T lymphocytes. J Immunol 2000; 165: 6723-6730.

29. Greenberg S, Di Virgilio F, Steinberg TH, Silverstein SC. Extracellular nucleotides mediate Ca2 + fluxes in $J 774$ macrophages by two distinct mechanisms. J Biol Chem 1988; 263: 10337-10343

30. Khakh BS, North RA. Neuromodulation by extracellular ATP and P2X receptors in the CNS. Neuron 2012; 76: 51-69.

31. Di Virgilio F. The therapeutic potential of modifying inflammasomes and NOD-like receptors. Pharmacol Rev 2013; 65: 872-905.

32. Tu MT, Luo SF, Wang CC, Chien CS, Chiu CT, Lin CC et al. P2Y(2) receptor-mediated proliferation of $\mathrm{C}(6)$ glioma cells via activation of Ras/Raf/MEK/MAPK pathway. $\mathrm{Br} J$ Pharmacol 2000; 129: 1481-1489.

33. Gerasimovskaya EV, Woodward HN, Tucker DA, Stenmark KR. Extracellular ATP is a proangiogenic factor for pulmonary artery vasa vasorum endothelial cells. Angiogenesis 2008; 11: $169-182$.

34. Falzoni S, Munerati M, Ferrari D, Spisani S, Moretti S, Di Virgilio F. The purinergic P2Z receptor of human macrophage cells. Characterization and possible physiological role. J Clin Invest 1995; 95: 1207-1216.

35. Surprenant A, Rassendren F, Kawashima E, North RA, Buell G. The cytolytic P2Z receptor for extracellular ATP identified as a P2X receptor (P2X7). Science 1996; 272: 735-738.

36. Ferrari D, Los M, Bauer MK, Vandenabeele P, Wesselborg S, Schulze-Osthoff K. P2Z purinoreceptor ligation induces activation of caspases with distinct roles in apoptotic and necrotic alterations of cell death. FEBS Lett 1999; 447: 71-75.

37. Adinolfi E, Melchiorri L, Falzoni S, Chiozzi P, Morelli A, Tieghi A et al. P2X7 receptor expression in evolutive and indolent forms of chronic B lymphocytic leukemia. Blood 2002; 99: 706-708.

38. Slater M, Danieletto S, Gidley-Baird A, Teh LC, Barden JA. Early prostate cancer detected using expression of non-functional cytolytic P2X7 receptors. Histopathology 2004; 44: 206-215.

39. Solini A, Cuccato S, Ferrari D, Santini E, Gulinelli S, Callegari MG et al. Increased P2X7 receptor expression and function in thyroid papillary cancer: a new potential marker of the disease? Endocrinology 2008; 149: 389-396.
40. Adinolfi E, Raffaghello L, Giuliani AL, Cavazzini L, Capece M, Chiozzi P et al. Expression of P2X7 receptor increases in vivo tumor growth. Cancer Res 2012; 72: 2957-2969.

41. Pellegatti P, Raffaghello L, Bianchi G, Piccardi F, Pistoia V, Di Virgilio F. Increased level of extracellular ATP at tumor sites: in vivo imaging with plasma membrane luciferase. PLOS One 2008; 3: e2599.

42. Martins I, Tesniere A, Kepp O, Michaud M, Schlemmer F, Senovilla L et al. Chemotherapy induces ATP release from tumor cells. Cell Cycle 2009; 8: 3723-3728.

43. Michaud M, Martins I, Sukkurwala AQ, Adjemian S, Ma Y, Pellegatti $P$ et al. Autophagy-dependent anticancer immune responses induced by chemotherapeutic agents in mice. Science 2011; 334: 1573-1577.

44. Sun X, Wu Y, Gao W, Enjyoji K, Csizmadia E, Muller CE et al. CD39/ENTPD1 expression by $\mathrm{CD} 4+$ Foxp3 + regulatory T cells promotes hepatic metastatic tumor growth in mice. Gastroenterology 2010; 139: 1030-1040.

45. Gabrilovich DI, Nagaraj S. Myeloid-derived suppressor cells as regulators of the immune system. Nat Rev Immunol 2009; 9: 162-174.

46. Bronte V, Apolloni E, Cabrelle A, Ronca R, Serafini P, Zamboni P et al. Identification of a $\mathrm{CD} 11 \mathrm{~b}(+) / \mathrm{Gr}-1(+) / \mathrm{CD} 31(+)$ myeloid progenitor capable of activating or suppressing CD8(+) T cells. Blood 2000; 96: 3838-3846.

47. Gabrilovich DI, Velders MP, Sotomayor EM, Kast WM. Mechanism of immune dysfunction in cancer mediated by immature Gr-1 + myeloid cells. J Immunol 2001; 166: 5398-5406.

48. Sinha P, Clements VK, Ostrand-Rosenberg S. Interleukin-13-regulated M2 macrophages in combination with myeloid suppressor cells block immune surveillance against metastasis. Cancer Res 2005; 65: 11743-11751.

49. Sinha P, Clements VK, Bunt SK, Albelda SM, Ostrand-Rosenberg S. Cross-talk between myeloid-derived suppressor cells and macrophages subverts tumor immunity toward a type 2 response. J Immunol 2007; 179: 977-983.

50. Huang B, Pan PY, Li Q, Sato Al, Levy DE, Bromberg J et al. Gr-1 + CD115 + immature myeloid suppressor cells mediate the development of tumor-induced $T$ regulatory cells and T-cell anergy in tumor-bearing host. Cancer Res 2006; 66: 1123-1131.

51. Serafini P, Mgebroff S, Noonan K, Borrello I. Myeloid-derived suppressor cells promote cross-tolerance in B-cell lymphoma by expanding regulatory T cells. Cancer Res 2008; 68: 5439-5449.

52. Liu C, Yu S, Kappes J, Wang J, Grizzle WE, Zinn KR et al. Expansion of spleen myeloid suppressor cells represses NK cell cytotoxicity in tumor-bearing host. Blood 2007; 109: 4336-4342.

53. Peranzoni E, Zilio S, Marigo I, Dolcetti L, Zanovello P, Mandruzzato S et al. Myeloidderived suppressor cell heterogeneity and subset definition. Curr Opin Immunol 2010; 22: 238-244.

54. Movahedi K, Guilliams M, Van den Bossche J, Van den Bergh R, Gysemans C, Beschin A et al. Identification of discrete tumor-induced myeloid-derived suppressor cell subpopulations with distinct T cell-suppressive activity. Blood 2008; 111: 4233-4244.

55. Youn JI, Nagaraj S, Collazo M, Gabrilovich DI. Subsets of myeloid-derived suppressor cells in tumor-bearing mice. J Immunol 2008; 181: 5791-5802.

56. Hammami I, Chen J, Bronte V, De Crescenzo G, Jolicoeur M. Myeloid-derived suppressor cells exhibit two bioenergetic steady-states in vitro. J Biotechnol 2011; 152: 43-48.

57. Foster JG, Carter E, Kilty I, MacKenzie AB, Ward SG. Mitochondrial superoxide generation enhances P2X7R-mediated loss of cell surface CD62L on naive human CD4 + T lymphocytes. J Immunol 2013; 190: 1551-1559.

58. Conti I, Rollins BJ. CCL2 (monocyte chemoattractant protein-1) and cancer. Semin Cancer Biol 2004; 14: 149-154.

59. Metelitsa LS, Wu HW, Wang H, Yang Y, Warsi Z, Asgharzadeh S et al. Natural killer T cells infiltrate neuroblastomas expressing the chemokine CCL2. J Exp Med 2004; 199 : 1213-1221.

60. Molon B, Ugel S, Del Pozzo F, Soldani C, Zilio S, Avella D et al. Chemokine nitration prevents intratumoral infiltration of antigen-specific T cells. J Exp Med 2011; 208: 1949-1962.

61. Ryzhov S, Novitskiy SV, Goldstein AE, Biktasova A, Blackburn MR, Biaggioni I et al. Adenosinergic regulation of the expansion and immunosuppressive activity of $\mathrm{CD} 11 \mathrm{~b}+$ Gr1 + cells. J Immunol 2011; 187: 6120-6129.

62. Lode HN, Xiang R, Varki NM, Dolman CS, Gillies SD, Reisfeld RA. Targeted interleukin-2 therapy for spontaneous neuroblastoma metastases to bone marrow. J Natl Cancer Inst 1997; 89: 1586-1594.

63. Pellegatti $\mathrm{P}$, Falzoni S, Pinton P, Rizzuto R, Di Virgilio F. A novel recombinant plasma membrane-targeted luciferase reveals a new pathway for ATP secretion. Mol Biol Cell 2005; 16: 3659-3665.

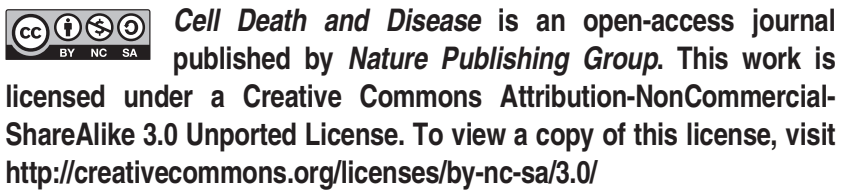

